\title{
Benzoquinonediimine ligands: synthesis, coordination chemistry and properties
}

\author{
Simon Pascal, Olivier Siri \\ Aix Marseille Univ, CNRS, UMR 7325, CINaM, Campus de Luminy, case 913, 13288 Marseille cedex \\ 09, France \\ E-mail: olivier.siri@univ-amu.fr
}

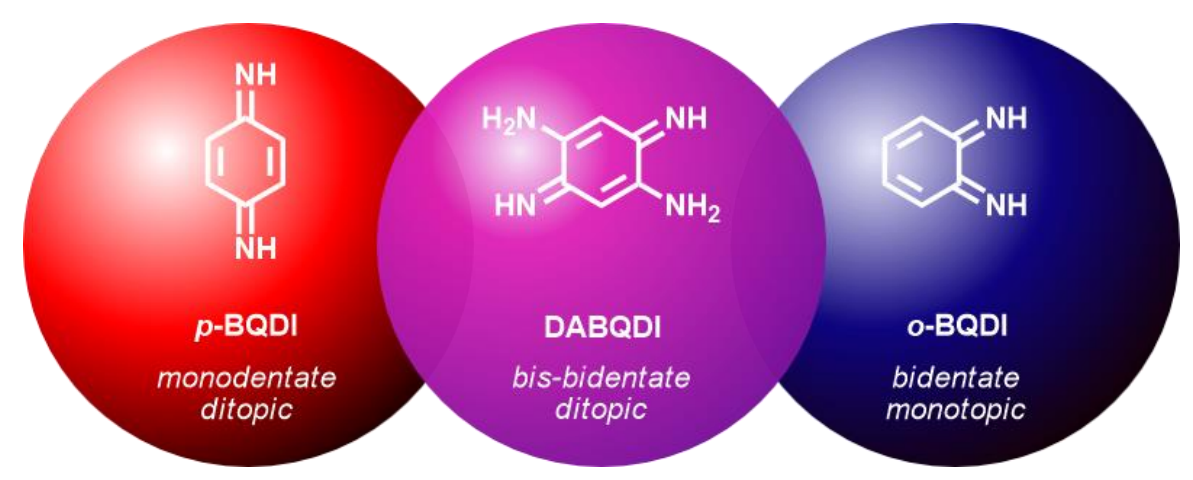

Abstract: This review covers the synthesis and properties of 2,5-diamino-1,4-benzoquinonediimines (DABQDI), and their use as ligand in coordination chemistry. Although reported more than a century ago, these molecules emerged as highly versatile ligands only from 1998, and are so far used for the synthesis of numerous complexes with remarkable properties. This exceptional versatility results from the possible tuning of the $\mathrm{N}$-substituents and the observation of an isomerization process upon coordination depending on the metal center. As such, these DABQDI can be also considered as ligands that combine the structural elements of ortho- and para-benzoquinonediimines (o-BQDI and $p$-BQDI) which are bidentate monotopic and monodentate ditopic ligands, respectively. These two classes of $B Q D I$ ligands are also reviewed in order to parallel their properties to those of the complexes based on DABQDI. 


\section{Introduction and scope}

Quinoidal molecules have received particular attention from chemists, physicists and biochemists as building block in the fields of dyes chemistry, conducting organic materials, supramolecular chemistry and pharmacology [1-6]. Over the last three decades, they have also been strongly investigated as ligand, for the design of complexes that could be used in a wide range of applications ranging from catalysis and molecular electronics, to magnetism or optics [7-10]. Among these quinoidal ligands, paraand ortho-benzoquinonediimines ( $p$ - and $o-B Q D I$ ) have a long history because of their easy access and their different coordination mode (mono- $v s$ bidentate) which allowed the preparation of numerous complexes (Chart 1). When 1,4-benzoquinonediimine ( $p$-BQDI) is substituted in positions 2 and 5 by an amine function $\mathrm{NH}_{2}$ (DABQDI), the coordination chemistry differs drastically and becomes much more versatile compared to $p$ - and $o-B Q D I$ ligands because of the possible $p \rightarrow 0$ isomerization of DABQDI. As a consequence, this latter can be considered as a ligand that combines the structural elements of these two BQDI which are bidentate monotopic and monodentade ditopic ligands, respectively. Curiously, DABQDI can be considered as an emerging class of versatile ligands by comparison with its oxygenated analogue (2,5-dihydroxy-1,4-benzoquinone DHBQ, see Chart 1) which has been extensively used in coordination chemistry for decades. The possible presence of $N$ substituents enlarges indeed the scope of these $\mathrm{N}_{4}$ ligands for embracing new challenging areas. The present review is the first attempt that aims to summarize the coordination chemistry of these three types of benzoquinonediimine ligands.

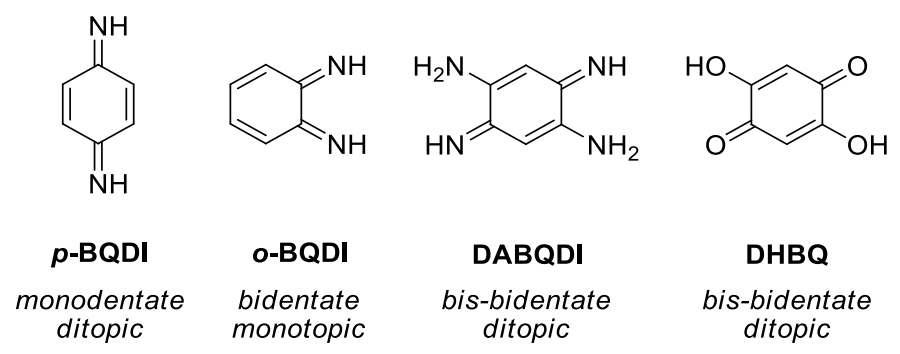

Chart 1. Benzoquinonediimines under the scope of this review and structure of dihydroxybenzoquinone.

In a first part, special attention will be devoted to the richness of the coordination chemistry of paraand ortho-benzoquinonediimines ( $p$-and $o-\mathrm{BQDI}$ ). While the position of the nitrogen atom within ditopic $p$-BQDI is ideal to develop conjugated complexes, the interest of $o-B Q D I$ isomer mainly lies in its bidentate character and multiple redox states. The second part will focus on the use of DABQDI (with or without $\mathrm{N}$-substituents) as a versatile ditopic and bis-bidentate $\mathrm{N}$-ligand for the design of coordination complexes featuring unique physico-chemical properties. These latter are relevant in several technological sectors, e.g. catalysis [11-13] or molecular materials (wires, switches, memories, ...) [14], by analogy with the well-known non-innocent ligands and mixed-valence complexes. The coordination and electronic assets let foresee a tremendous potential since this type of ligands can be employed to develop polynuclear and conjugated complexes. Particular emphasis will be given to the optical and redox properties of the metal ligand complexes. Aside, the synthetic pathways to access these ligands 
and modify their substitution will be also described in order to highlight the versatility of this fascinating class of $12 \pi$-electrons quinones.

\section{Coordination chemistry of para- and ortho-benzoquinonediimines}

Para- and ortho-benzoquinonediimines (Chart 1 ) are respectively obtained from $p$ - and $o$ phenylenediamine (PDA) following chemical, aerobic or metal-assisted oxidation of the species. Historically, these precursors are already well-known as oxidative hair colorants (for more than a century) $[15,16]$ or as precursors for the synthesis of numerous dyes such as phenazines and azaacenes [17-22], which found several applications, notably as chemical and biological probes or in organic electronics [23-25]. Although the metalation of BQDI has been already reviewed, this section aims to exemplify their use as ligand in coordination chemistry and the diversity of the obtained complexes which will figure as basis for further description of DABQDI-based architectures (see Section 4).

\section{1. $p$-benzoquinonediimine ligands}

Ludi and co-workers reported in 1975 the coordination of ruthenium(II)pentaamine with $p$-BQDI (Scheme 1) [26]. A tricationic complex $\mathbf{1} \cdot \mathbf{H}^{+}$was isolated as purple crystals, featuring intense visible absorption centered at $522 \mathrm{~nm}$. The dramatic red-shift of absorption compared to the free diimine ligand $\left(\lambda_{\max }=322 \mathrm{~nm}\right)$ is attributed to a ligand-to-metal charge transfer $(\mathrm{LMCT})$ process. Disappearance of this transition is monitored upon two-electron reduction of complex $\mathbf{1} \cdot \mathbf{H}^{+}$, which presumably generates the aromatic form of the ligand $\left(\lambda_{\max }=286 \mathrm{~nm}\right)$. Deprotonation of complex $\mathbf{1} \cdot \mathbf{H}^{+}$occurred in basic aqueous solution, generating the dicationic species 1, featuring red-shifted absorption maximum at 562 $\mathrm{nm}$, presumably due to increased LMCT. A pKa of 10.6 was determined for this system, which underlines the higher basicity of the complex compared to the free $p$-BQDI ligand ( $\mathrm{KKa}=5.75$ ). Furthermore, the introduction of methyl groups at the iminium extremity (2a) and extension of conjugation using a central naphthalene ring (3) are efficient methods to further red-shift the absorption up to the orange spectral range ( $\lambda_{\max }=568$ and $599 \mathrm{~nm}$, respectively). Afterwards, the same group reported in 1985 analogous complexes introducing osmium(II) (2b), and consequently evidenced the negligible effect of the transition metal on the absorption properties [27]. 


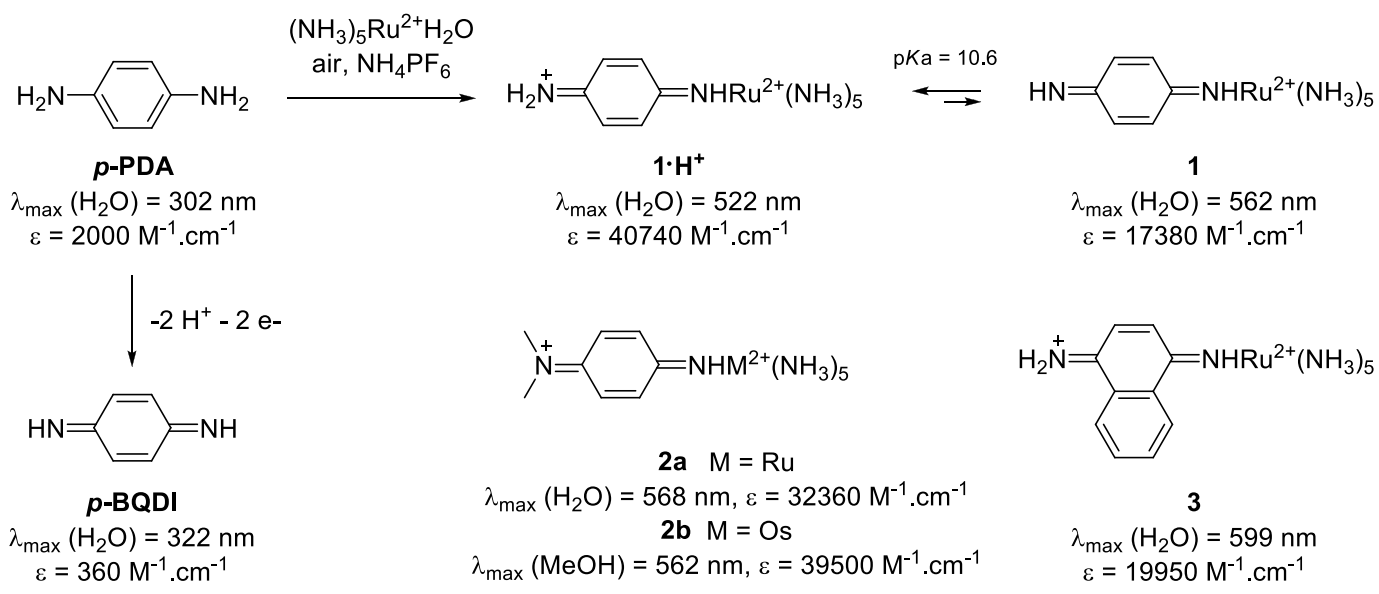

Scheme 1. Complexes of $p$-BQDI and corresponding lower energy absorption characteristics [26, 27].

In 1981, Ludi et al. managed to prepare a dinuclear ruthenium complex incorporating a $p$-BQDI bridge (4, Figure 1) by mixing $p$-PDA in an aqueous solution of $\left[\left(\mathrm{NH}_{3}\right)_{5} \mathrm{Ru}\left(\mathrm{H}_{2} \mathrm{O}\right)\right]^{2+}[28]$. Interestingly, the absorption spectrum of $\mathbf{4}$ exhibits three intense low energy bands in the red and near-infrared (NIR) ranges which were attributed to intervalence charge transfer (IVCT) transitions [29]. Cyclic voltammetry of 4 in acetonitrile/water reveals oxidation and reduction at 0.82 and $0.21 \mathrm{~V} v s$. NHE, respectively, while the reduction of the $p$-BQDI ligand to $p$-PDA presumably occurs ca. $-1 \mathrm{~V}$. The comproportionation equilibrium was estimated to be shifted towards formation of the mixed-valence complex $\left(K_{\mathrm{com}} \sim 10^{10}\right)$. Moreover, combined NMR, EPR and crystallographic analysis corroborated the mixed-valence nature of this $p$-BQDI-bridged $\mathrm{Ru}(\mathrm{II}) / \mathrm{Ru}(\mathrm{III})$ complex.

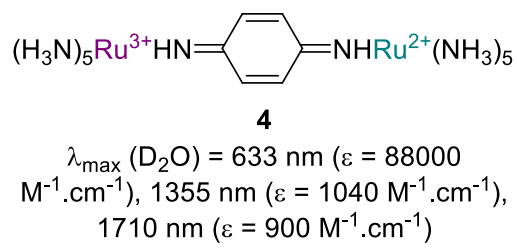

Figure 1. Structure of dinuclear complex 4 [28].

Herington reported in 1959 the synthesis of linear $\left[(\mathrm{CN})_{5} \mathrm{Fe} \cdot \mathrm{HN}-\mathrm{C}_{6} \mathrm{H}_{4}-\mathrm{NH} \cdot \mathrm{Fe}(\mathrm{CN})_{5}\right]\left[\mathrm{Zn}_{3}\right]$ from $p$ phenylenediamine and a disodium pentacyanoamminoferrate precursor in aqueous $\mathrm{NaOH}$ solution. However the poor solubility of the complex did not permit the investigation of its properties in solution [30]. In 1991, a novel synthetic procedure allowed to isolate this dinuclear complex as a water-soluble sodium salt $\mathbf{5 a}$ (Scheme 2) [31]. Upon lowering the $\mathrm{pH}$, conversion to the mononuclear complex $\mathbf{6}$ was evidenced, accompanied by a slight hypsochromic shift of the absorption maximum to $676 \mathrm{~nm}$. Further acidification of the solution triggered the protonation of the BQDI ligand and a red-shift of the absorption towards the far red region $\left(\lambda_{\max }=725 \mathrm{~nm}\right.$ for $\left.\mathbf{6} \cdot \mathbf{H}^{+}\right)$. Unlike the system $\mathbf{1}$, which LMCT transition undergoes blue-shift upon protonation, the lower energy transition in $\mathbf{6}$ is attributed to a metal-to-ligand charge transfer (MLCT), transition which is therefore shifted to lower energy upon protonation. 


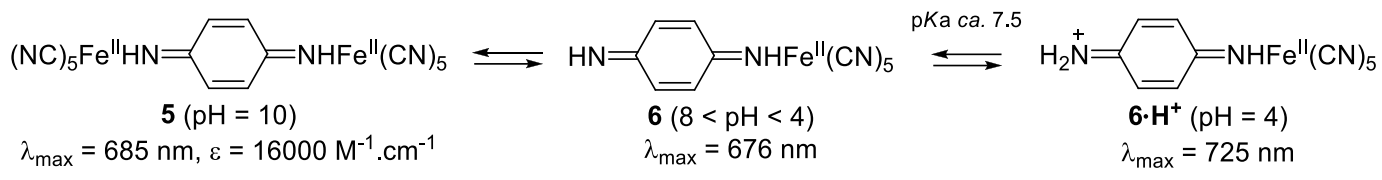

Scheme 2. Dinuclear and mononuclear complexes of $p$-BQDI pentacyanoferrate [31].

Hirao, Moriuichi and co-workers developed numerous $\pi$-conjugated complexes introducing $\mathrm{N}$ substituted $p$-BQDI 7 ( $N, N$-bis(4'-aminophenyl)-1,4-quinonediimine) [32] ligands as bridging spacers (Scheme 3) [33]. On the one hand, using a Pd precursor bearing a tridentate ligand (11a), a bimetallic complex 8a was obtained [34]. This conjugated complex that exhibits absorption centered in the NIR region $\left(\lambda_{\max }=806 \mathrm{~nm}\right.$ ) could be reversibly and stepwise reduced: first to the corresponding semiquinone

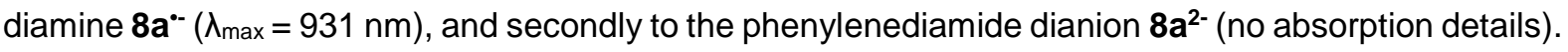
EPR analysis of 8a*- shows that the $p$-BQDI bridge behaves as a non-innocent ligand since the unpaired electron is mainly localized on the ligand and weakly delocalized on the Pd nucleus (Figure 2). On the other hand, while the reaction of ligand 7 with $\left[\mathrm{PdCl}_{2}(\mathrm{MeCN})_{2}\right]$ induces the polymerization of the complex (9), treatment with an ethylenediamine- $\mathrm{Pd}(\mathrm{II})$ precursor leads to the formation of the trimetallic macrocyle 10, featuring a broad absorption transition centered ca. $800 \mathrm{~nm}$ [35].

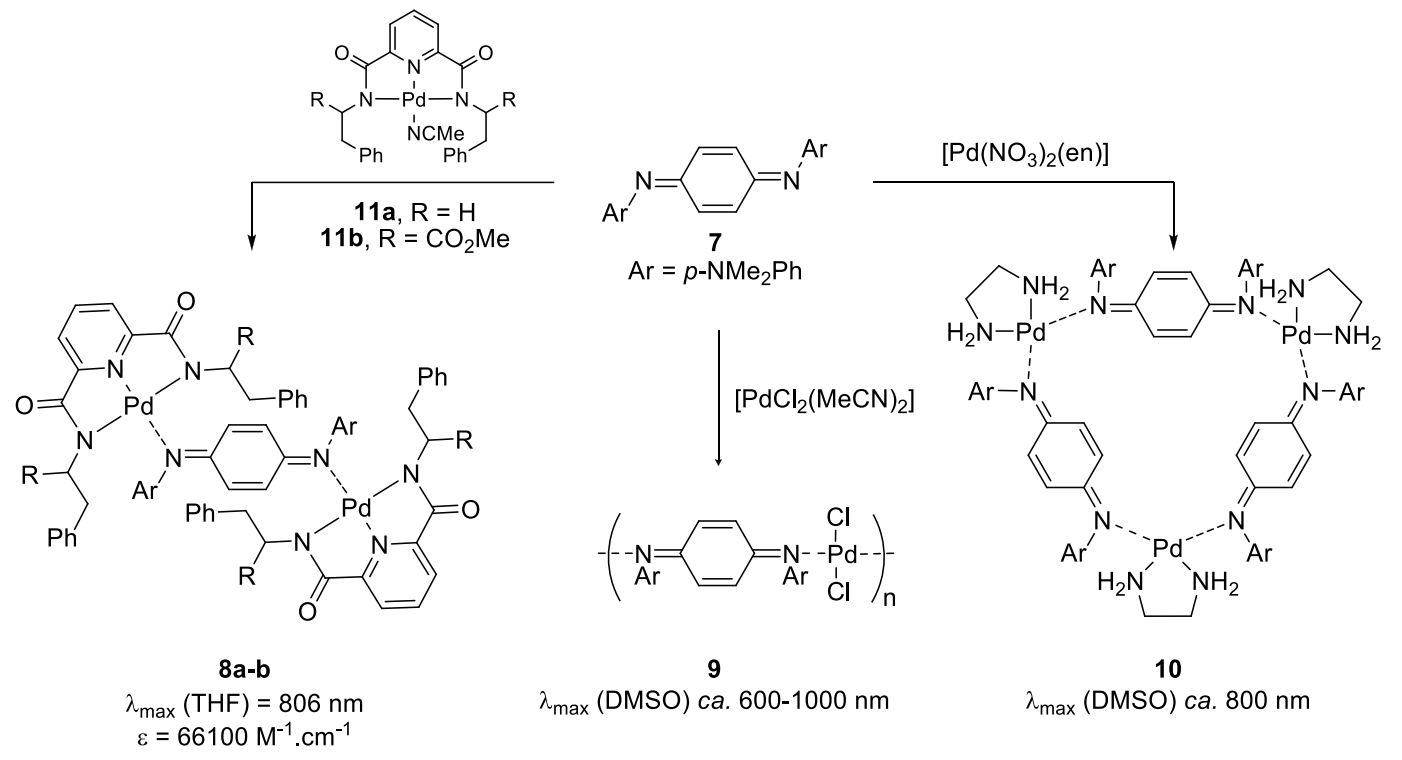

Scheme 3. Conjugated polynuclear Pd complexes introducing p-BQDI ligands [34, 35]. 


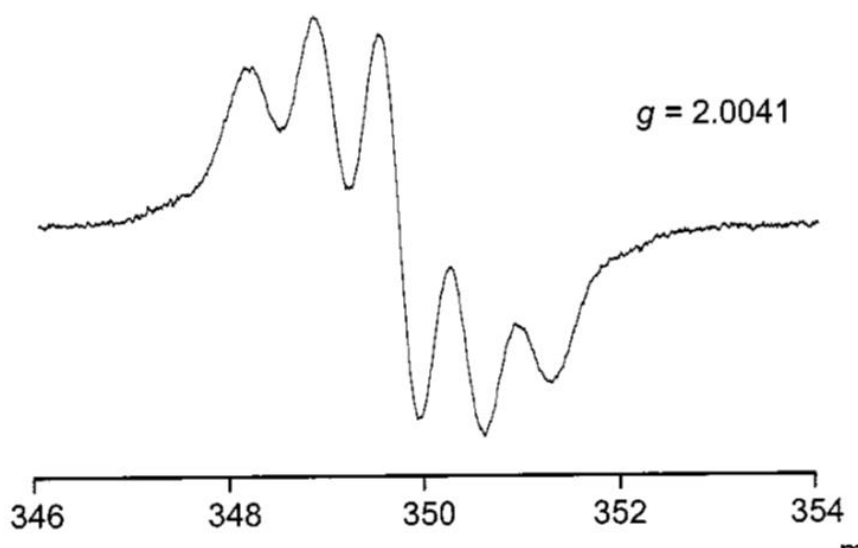

Figure 2. EPR spectrum of $\mathbf{8 a}$ *- in THF at 290K. Reproduced with permission from Ref. [34].Copyright WILEY-VCH Verlag $\mathrm{GmbH}, 2001$.

Coordination complexes analogue to 8 found a particular interest in the development of chiral conducting polymers [36]. Similar architectures were developed using the chiral tridendate ligand 11b to obtain conjugated dinuclear complex $\mathbf{8 b}$ exhibiting electronic circular dichroism (ECD), induced by the complexation to the quinoidal ligand, up to the NIR spectral region (Figure 3) [37, 38].

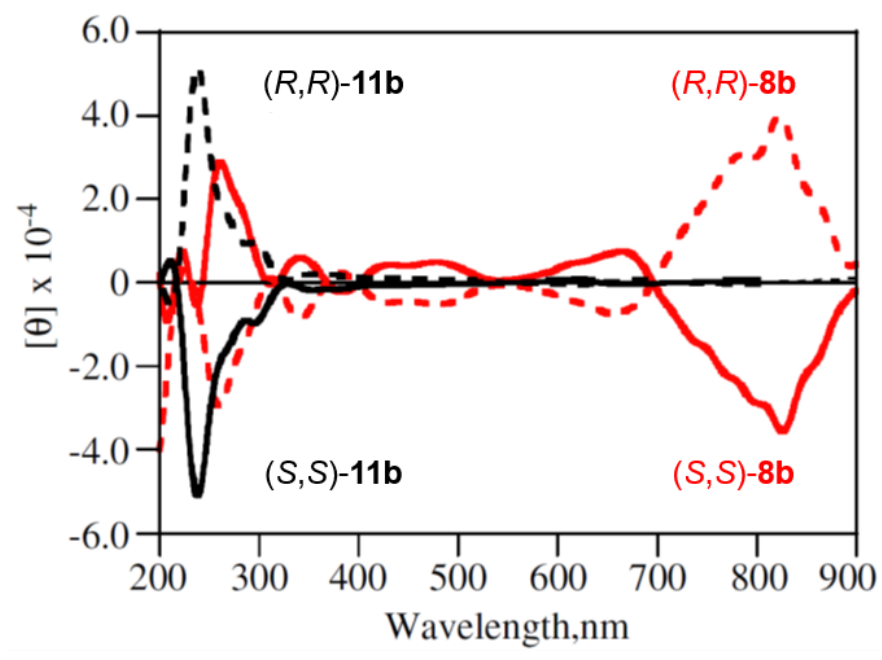

Figure 3. UV-Vis-NIR ECD spectra of ligand $11 \mathbf{b}\left(10^{-4} \mathrm{M}\right)$ and complex $8 \mathbf{b}\left(5.10^{-5} \mathrm{M}\right)$ in $\mathrm{CH}_{2} \mathrm{Cl}_{2}$. Figure was reproduced from ref. [37] with permission of the copyright holders.

Finally, beyond the scope of the simple $p$-BQDI ligand, it is worthy to note that the same collaborators reported vanadium(IV) complexes of emeraldine [39] and investigated the redox switching of various polyaniline and quinonediimine derivatives introducing ruthenium bipyridine [40-42] or ferrocene extremities $[43,44]$.

\section{2. $o$-benzoquinonediimines ligands}

While only few works relate the use of $p$-BQDI as ligand, the $o-B Q D I$ isomer has been reported in a wider range of studies and its coordination chemistry has been extensively reviewed previously $[11,14$, 
45-48]. The attraction for such quinone is mainly explained by the fact that $o-B Q D I$ is a well-established non-innocent ligand (Scheme 4), i.e. it exhibits multiple redox states that enrich possible electron transfer within metal complexes. As such, these redox-active ligands can act as electron reservoirs to tune the electronic properties of a metal catalyst and/or play a role in catalytic processes [11-13]. Moreover, several ruthenium-based complexes featuring o-quinone ligands have found potential interest in biology as DNA-binding or cytotoxic agents [49-51]. In consequence, only few instances will be presented, with principal aim to establish a comparison basis with complexes introducing DABQDI ligands (see Section 4).

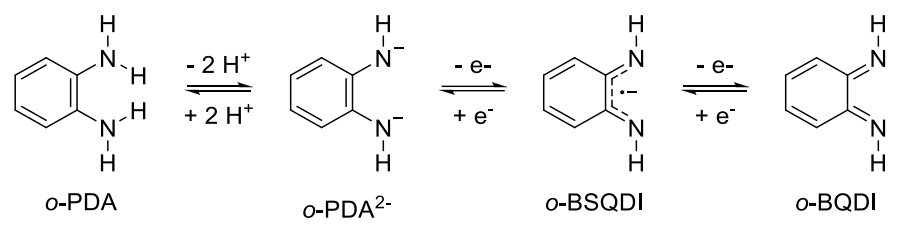

Scheme 4. Redox forms associated with o-phenylene diamine (o-PDA): dianion (o-PDA ${ }^{2-}$ ), o-benzosemiquinone diimine (o-DBSQ) and o-benzoquinonediimine (o-BQDI).

Seminal work from Feigl and Fürth in 1927 reports the formation of a violet complex upon mixing $\mathrm{Ni}^{2+}$ and o-phenylenediamine (o-PDA) in aqueous ammonia [52]. Further mass spectrometry investigations of the complex and of those of other metal centers ( $\mathrm{Pd}, \mathrm{Pt}$, Co analogues 13-15) evidenced the structure of neutral $\mathrm{Ni}_{[}\left[\mathrm{C}_{6} \mathrm{H}_{4}(\mathrm{NH})_{2}\right]_{2} 12$ [53-55]. Even if the first proposition of the chemical structure of these complexes was described as its aromatic form, questions have been raised in 1955 concerning the possibility of a quinonediimine form of the ligand, according to Bardodej [56]. This hypothesis could be confirmed based on a crystallographic analysis of $\mathbf{1 2}$ that demonstrated a quinoidal character of the ligands in view of the bond length alternation within the $\mathrm{C}_{6} \mathrm{H}_{4}(\mathrm{NH})_{2}$ cycles (see 16 in Chart 2) [57]. Polarography experiments of diamagnetic series 12-15 revealed reversible one-electron oxidations and reductions leading respectively to the $\left[M-N_{4}\right]^{2+}$ and $\left[M-N_{4}\right]^{2-}$ species. These results paved the way in 1975 for the use of these complexes in semiconducting metal-organic salts [58]. Absorption measurements in DMSO solution highlight the particularly low energy bands located in the NIR range for $\mathrm{Ni}, \mathrm{Pd}$ and $\mathrm{Pt}$ complexes, and up to $1135 \mathrm{~nm}$ for the Co derivative. In the case of nickel complex 12, it was shown that substitution of one nitrogen of the ligand with a phenyl ring lead to exceptional batchochromic and hyperchromic shifts of the absorption, with a maximum at $823 \mathrm{~nm}$ for 17 [59]. In this instance, the authors presumed that complex 17 introduces two o-BSQDI ligands that could be successively and reversibly reduced to the generate $\mathrm{Ni}(0-\mathrm{BSQDI})(0-\mathrm{PDA})^{-}$then $\mathrm{Ni}(0-\mathrm{PDA}) 2^{2-}$ species at -0.69 and $-1.37 \mathrm{~V} v s$. $\mathrm{Ag} / \mathrm{AgCl}$, respectively. 
<smiles>[M]C1Nc2ccccc2N1Nc1nc2ccccc2[nH]1</smiles>

$12, \mathrm{M}=\mathrm{Ni}$

$\lambda_{\max }=790 \mathrm{~nm}, \varepsilon=54900 \mathrm{M}^{-1} . \mathrm{cm}^{-1}$

$13, \mathrm{M}=\mathrm{Pd}$

$\lambda_{\max }=780 \mathrm{~nm}, \varepsilon=48200 \mathrm{M}^{-1} \cdot \mathrm{cm}^{-1}$

$$
14, \mathrm{M}=\mathrm{Pt}
$$

$\lambda_{\max }=782 \mathrm{~nm}, \varepsilon=3310 \mathrm{M}^{-1} \cdot \mathrm{cm}^{-1}$

$15, M=C_{0}$

$\lambda_{\max }=1135 \mathrm{~nm}, \varepsilon=3840 \mathrm{M}^{-1} \cdot \mathrm{cm}^{-1}$<smiles>c1ccc2[nH][n+]3[nH]c4ccccc4c3[nH][nH]c2c1</smiles>

16<smiles>PC1=CC=CN(N2Nc3ccccc3N2c2ccccc2)c2ccccc21</smiles>

17

$\lambda_{\max }(\mathrm{MeCN})=823 \mathrm{~nm}$

$\varepsilon=416900 \mathrm{M}^{-1} \cdot \mathrm{cm}^{-1}$

Chart 2. Series of [M-N4] type complexes 12-15 reported by Balch and Holm (absorption in DMSO) [55], structures of $\mathrm{Ni}\left[\mathrm{C}_{6} \mathrm{H}_{4}(\mathrm{NH})_{2}\right]_{2} 16$ [57] and $\mathrm{N}$-substituted analogue 17 [59].

In 1973, Goedken and Christoph reported the isolation of a purple (o-BQDI)tetracyanoiron(II) complex and established the quinoidal nature of the ligand for this type of complex [60]. Shortly afterwards, Warren published a comparative study of o-BQDI complexes, including cobalt (18) and iron (19) derivatives (Chart 3), the former being obtained either from tris complex $\mathbf{2 0}$ or by oxidation of $\mathbf{1 5}$ in presence of sodium iodide [61]. Such series allows to highlight that the first oxidation potentials of complexes 16, 18 and 19 was highly dependent on the metal, in the following order: $\mathrm{Ni}(+0.11 \mathrm{~V})<\mathrm{Co}$ $(-0.15 \mathrm{~V})<\mathrm{Fe}(-0.36 \mathrm{~V})$ in acetonitrile, their first reduction potential being located in a smaller range (-0.78 to $-0.89 \mathrm{~V} v$ s. SCE). The series of hexacoordinated complexes $\mathbf{2 0 - 2 2}$ were described as colorful compounds and display strong absorption in the red region, the lower energy transition being attributed to a MLCT [62]. By comparison with bipyridine (bipy) ligand, o-BQDI is easier to reduce and therefore acts as a stronger $\pi$-acceptor. The particularly efficient $\pi$-backbonding has been studied in depth by Lever et al. in the case of Ru"l[ $\left.\left(\mathrm{NH}_{3}\right)_{2} \mathrm{Cl}_{2}(0-\mathrm{BQDI})\right]$ complex $[63,64]$. Interestingly, this complex was also reported to undergo disproportionation in presence of acid to yield $\mathrm{Ru}^{\prime \prime \prime I}\left[\left(\mathrm{NH}_{3}\right)_{2} \mathrm{Cl}_{2}(\mathrm{o}-\mathrm{BQDI})\right]^{+}$and $\mathrm{Ru}^{\prime \prime \prime}\left[\left(\mathrm{NH}_{3}\right)_{2} \mathrm{Cl}_{2}(\mathrm{O}-\mathrm{PDA})\right]^{+}$[65]. Such proton-induced and $\mathrm{pH}$-dependent disproportionation may find potential interest in the screening of catalytic and biological processes involving non-innocent ligands. Mixed complexes introducing o-PDA and o-BQDI ligand were successively reported: increasing the number of aromatic ligand in $\mathrm{Ru}\left[(\mathrm{BQDI})_{\times}(0-\mathrm{PDA})_{3-x]}\right]\left[\mathrm{PF}_{6}\right]_{2}$ being principally accompanied by a blue-shift of the absorption ( $\lambda_{\max }=544$ and $468 \mathrm{~nm}$ for $\mathrm{x}=2$ and 1 , respectively) $[66,67]$. 


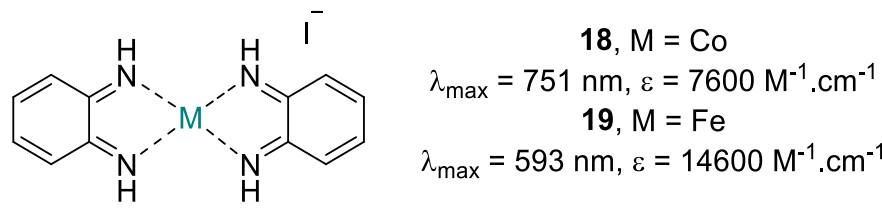

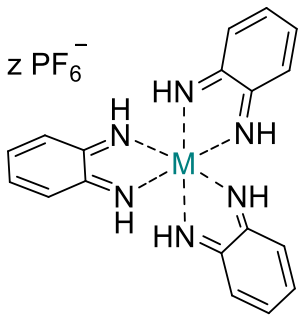

$$
\begin{gathered}
\text { 20, M = Co, } z=1 \\
\lambda_{\text {max }}=769 \mathrm{~nm}, \varepsilon=10000 \mathrm{M}^{-1} \cdot \mathrm{cm}^{-1} \\
\text { 21, M = Fe, z=2 } \\
\lambda_{\max }=701 \mathrm{~nm}, \varepsilon=17200 \mathrm{M}^{-1} \cdot \mathrm{cm}^{-1} \\
\text { 22, M = Ru, z=2 } \\
\lambda_{\max }=671 \mathrm{~nm}, \varepsilon=12700 \mathrm{M}^{-1} \cdot \mathrm{cm}^{-1}
\end{gathered}
$$

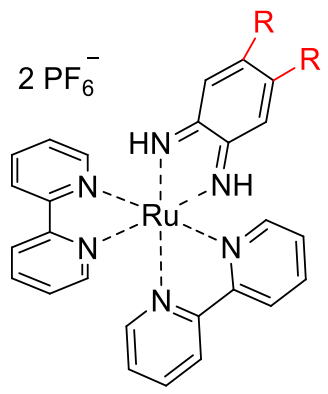

$$
\begin{aligned}
23, \mathrm{R}=\mathrm{OCH}_{3} \\
\lambda_{\text {max }}=667 \mathrm{~nm}, \varepsilon=251 \mathrm{M}^{-1} \cdot \mathrm{cm}^{-1} \\
24, \mathrm{R}=\mathrm{CH}_{3} \\
\lambda_{\text {max }}=730 \mathrm{~nm}, \varepsilon=214 \mathrm{M}^{-1} \cdot \mathrm{cm}^{-1} \\
25, \mathrm{R}=\mathrm{H} \\
\lambda_{\text {max }}=752 \mathrm{~nm}, \varepsilon=550 \mathrm{M}^{-1} \cdot \mathrm{cm}^{-1} \\
26, \mathrm{R}=\mathrm{Cl} \\
\lambda_{\max }=791 \mathrm{~nm}, \varepsilon=117 \mathrm{M}^{-1} \cdot \mathrm{cm}^{-1}
\end{aligned}
$$

Chart 3. Bis and tris o-BQDI complexes and absorption data in $\operatorname{MeCN}[61,68]$.

Substitution of the quinonediimine ligand within structures 23-26 depicted in Chart 3 is accompanied by absorption and redox potential shifts that can be correlated to the corresponding Hammett parameters for each substituent [64, 68]. Not surprisingly, easier reductions are measured with increasing electron-withdrawing functions, together with bathochromic shift of the lower energy transition, characterized by a quite low extinction coefficients $\left(\varepsilon<600 \mathrm{M}^{-1} . \mathrm{cm}^{-1}\right)$. Controlled reduction allowed to record the absorption spectra of the $o-B S Q D I$ and $o$-PDA forms of the ligand, revealing nonnegligible optical shifts. The authors were able to ascribe most of the transitions observed, the lower energy band in $25(\mathrm{R}=\mathrm{H}$, band 5 in Figure 4) being for instance attributed to a MLCT, and the second transition (ca. $500 \mathrm{~nm}$, band 4 in Figure 4) having a mixed distribution between ligand and metal (defined as a metal-ligand to metal-ligand transition (MLML)). While, the reduction to the $o$-BSQDI ligand triggers the apparition of absorption transitions at 900 and $625 \mathrm{~nm}$ (bands 10 and 9, Figure 4), further reduction to the $o$-PDA form of the ligand leads to a blue-shift of the absorption maximum to $478 \mathrm{~nm}$ (band 13, Figure 4). The reader interested in the rationalization and tuning of the 0 -BSQDI ligand is invited to consult works by Wieghardt et al. that deliver complete experimental and theoretical investigations of semiquinone-based iron, ruthenium, cobalt, nickel and palladium complexes [69-74]. 


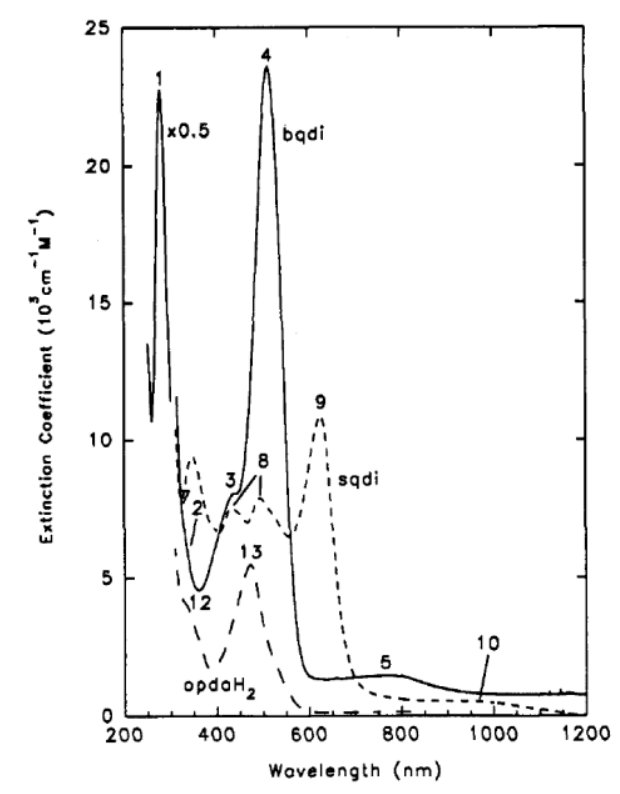

Figure 4. Absorption spectra of complexes $\left[R u(b i p y)_{2}(o-P D A)\right]^{2+}$ (dashed line), $\left[R u(b i p y)_{2}(o-B S Q D I)\right]^{+}$(dotted line) $\left[\mathrm{Ru}(\mathrm{bipy})_{2}(\mathrm{o}-\mathrm{BQDI})\right]^{2+}$ (plain line) in MeCN. Reprinted with permission from Ref. [68]. Copyright1993 American Chemical Society.

\section{Synthesis and properties of 2,5-diamino-benzoquinonediimines}

\subsection{Synthesis}

\subsubsection{Oxidation of tetraaminobenzene}

By comparison with $o$ - and $p$-PDA, tetraaminobenzene (TAB) is a highly electron rich aromatic compound that is potentially of great interest for the development of organic architectures and coordination complexes. However, the prompt aerial oxidation to DABQDI does not facilitate its usage but reveals instead to be a convenient method to access quinoidal systems. Historically, Nietzki brought to light the spontaneous oxidation of TAB under aerobic conditions in 1887 [75, 76]. Nakata et al. reported in 2005 the sublimation of unsubstituted DABQDI on a CsI plate cooled by closed-cycle refrigeration at $15 \mathrm{~K}$ but the compound was not fully characterized [77]. Although this molecule was first mentioned 130 years ago, the synthesis and full characterization of the unsubstituted DABQDI ligand has been published only in 2014 (Scheme 5) [78], the key feature being the precipitation of DABQDI in $\mathrm{MeOH}$ right after its formation in order to prevent further side reactions (hydrolysis, reaction with $\mathrm{TAB}$, further oxidation...).

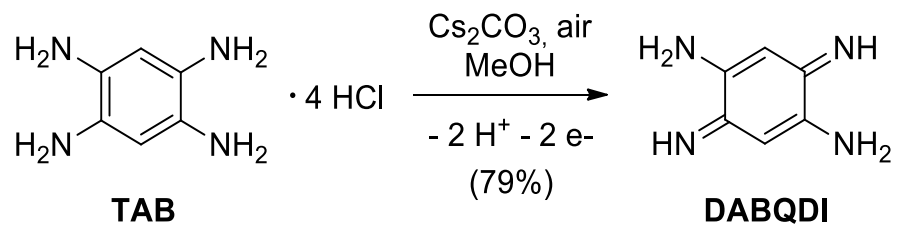

Scheme 5. Aerobic synthesis of DABQDI from TAB [78]. 


\subsubsection{Self-condensation of anilines}

Structures derived from DABQDI have been source of many discussions since the end of the nineteenth century, especially during the development of the indulines and other parent dyes derived from anilines [79]. Historically, the first example of DABQDI derivative was the azophenine $\mathbf{2 7}$ depicted in Scheme 6, which formation occurs through self-condensation of aniline with poor yield due to the production of several by-products. If this quinone was discovered by Kimich in 1875, its constitution formula was only established in 1888 by Fischer and Hepp [80, 81]. The next year, Bandrowski's work on the oxidation of $p$-PDA led to the isolation of the famous base named after him (Scheme 6) [82]. The structure of Bandrowski's base $\mathbf{2 8}$ was proposed by Green in 1913 and elucidated by Lauer 25 years later [83-85]. Aspects of this compound were intensively studied during the twentieth century due to occurrences in hair dyeing related dermatitis [86-88]. More recently, crystal structures of 27 and 28 have been reported, bringing an ultimate characterization of these historical DABQDI derivatives (Figure 5) [89, 90]. Interestingly, two molecular structures of azophenine 27 were reported as triclinic and orthorhombic polymorphs, showing different orientation of the phenyl rings and stabilized by weak $\mathrm{C}-\mathrm{H} \cdots \pi$ interactions or $\pi-\pi$ stacking in the crystal, respectively $[89,91]$.

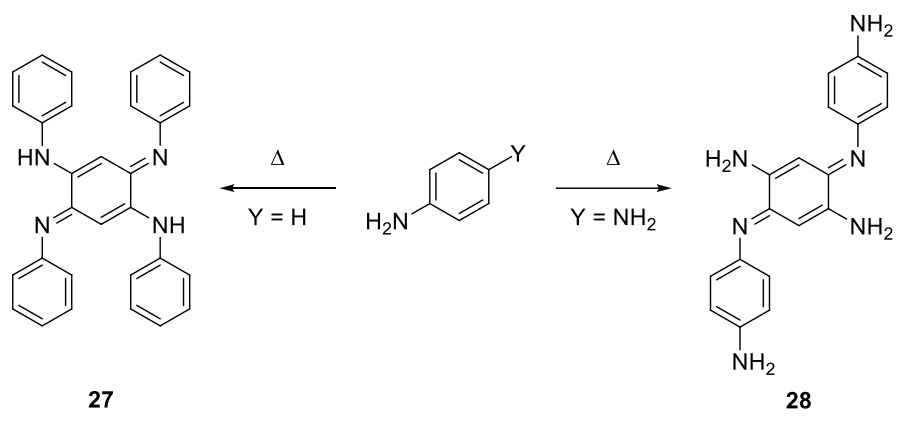

Scheme 6. Synthesis of historical DABQDI derivatives [80, 82].

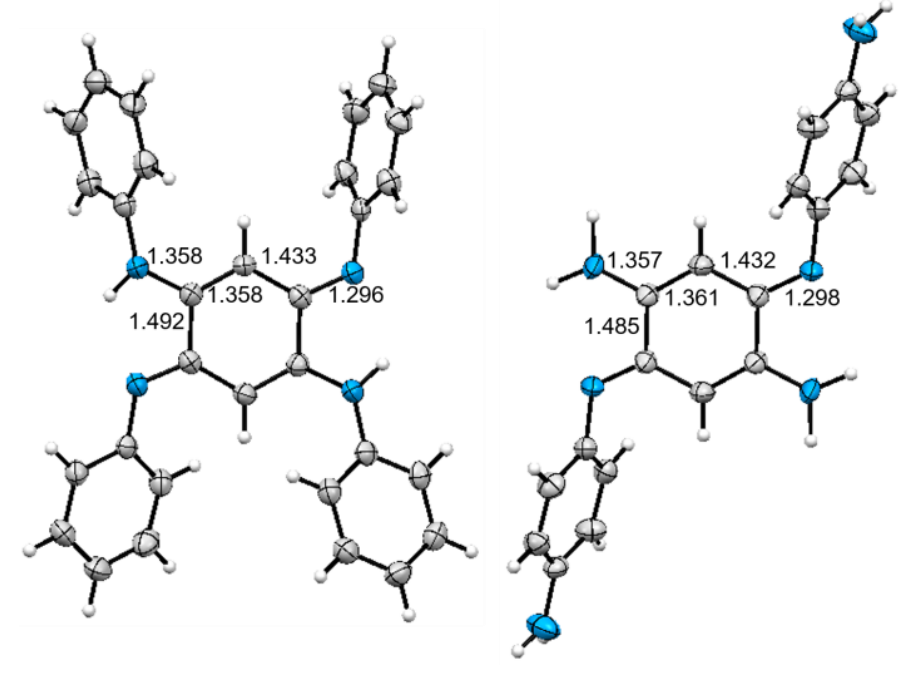

Figure 5. Structure and selected bond lengths $(\AA \AA)$ of azophenine 27 (left, [89]) and Bandrowski's base 28 (right, [90]); Anisotropic displacement parameters at $50 \%$. 


\subsubsection{Acylation reaction}

Several general strategies were reported for the introduction of substituted amines on DABQDI. Although the DABQDI, azophenine and Bandrowski's base have been known for more than a century, the first alternative to prepare $\mathrm{N}$-substituted analogues has been only reported in 2000 by Braunstein and Siri [92, 93]. This method - depicted in Scheme 7 - lies in the substitution of TAB using an acyl chloride reagent to form the aromatic derivative 29-a-c. The resulting amide functions are reduced in presence of $\mathrm{LiAlH}_{4}$, providing the intermediate 30a-c which undergoes spontaneous oxidation during aerobic workup, by analogy with TAB. Functionalized quinones 31a-c are then isolated with moderate to good yields mainly depending on the steric influence of the amide substituents.

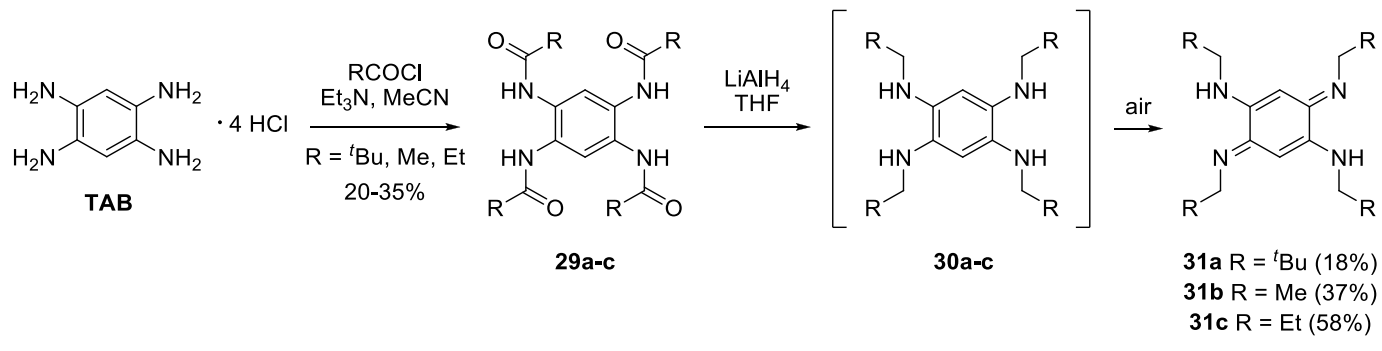

Scheme 7. Acylation of TAB to access $N$-substituted DABQDI derivatives [92, 93].

Aside, a multi-step procedure from diamino-dinitro-benzene derivatives allowed to access unsymmetrically $\mathrm{N}$-substituted DABQDI (Scheme 8) [94]. Acylation of 4,5-dinitrobenzene-1,2-diamine (32) leads to the formation of compound $\mathbf{3 3}$ with an excellent yield, this latter being converted to $\mathbf{3 4}$ using $\mathrm{SnCl}_{2}$ as reducing agent. Treatment with a different acyl chloride allows to form tetraamidobenzene $\mathbf{3 5}$ which does not undergo aerobic oxidation because of the electron-withdrawing amide functions. Their reduction with $\mathrm{LiAlH}_{4}$ converts 35 into its corresponding tetraamine 36 (not isolated), that is readily oxidized in presence of air to yield the target quinone $\mathbf{3 7}$ as a yellow solid.

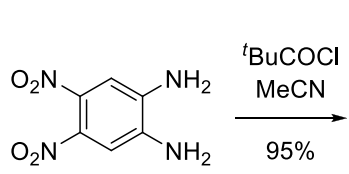

32
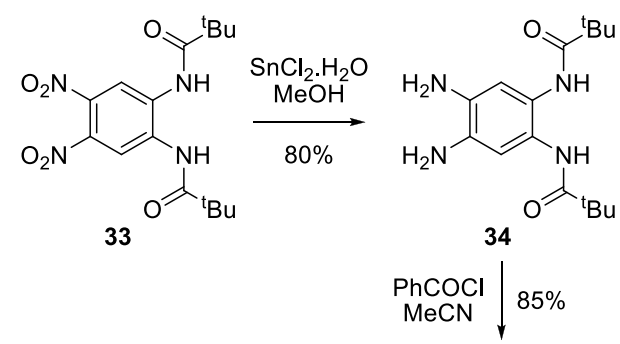<smiles>CC(C)(C)[N+](C)(C)C(=O)NCc1ccccc1</smiles>

37

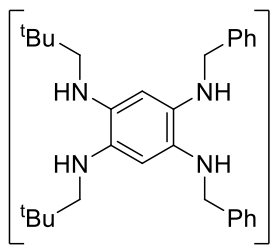

36

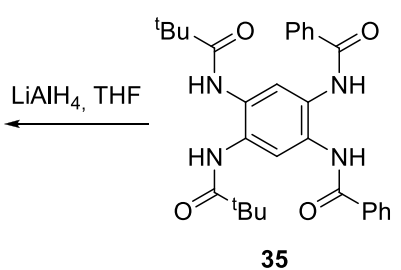

35

Scheme 8. Access to unsymmetrical $N$-substituted DABQDI derivatives [94]. 


\subsubsection{Buchwald-Hartwig coupling reaction}

An alternative method of $\mathrm{N}$-functionalization is based on the direct coupling of amines on the tetrabromobenzene precursor 38 using the Buchwald-Hartwig reaction [95-97]. $\mathrm{N}$-alkyl and $\mathrm{N}$-aryl derivatives $\mathbf{3 9}$ are obtained with good to quasi-quantitative yields (Scheme 9 ). Interestingly, the nature of the substitution appears to influence the rate of aerobic oxidation to the corresponding quinone $\mathbf{4 0}$ : while the conversion occurs within few hours for arylamine derivatives, few days are necessary for the oxidation of the alkylamine analogues. By analogy with TAB tetrachloride, the oxidation of arenes $\mathbf{3 9}$ to quinones $\mathbf{4 0}$ can be prevented through protonation of the nitrogen atoms with $\mathrm{HCl}$ before their isolation.

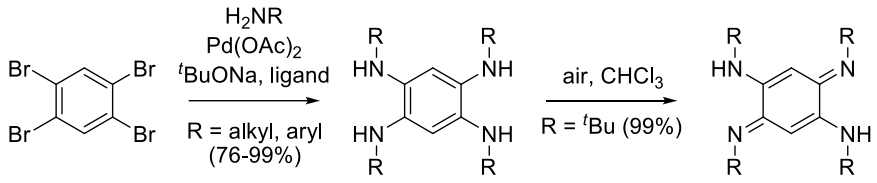

38

39

40

Scheme 9. N-substituted DABQDI via Pd(II) cross-coupling reaction [96].

\subsubsection{Michael addition}

Harvey and co-workers have recently disclosed a new pathway towards $N$-substituted DABQDI [98]. The $p$-benzoquinone reacted with the aniline derivative 41 in presence of excess $\mathrm{TiCl}_{4}$ and a base to yield quinone 42 (Scheme 10). The synthon $\mathbf{4 2}$ was relevant to study the excited state of an emeraldine model and has later been used for the preparation of luminescent azophenine-Pt organometallic complexes [99].

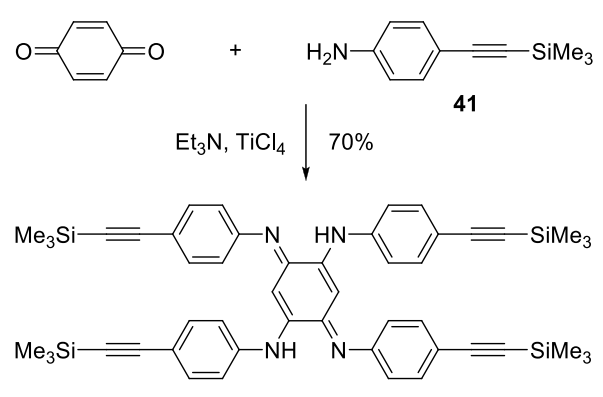

42

Scheme 10. Preparation of DABQDI from p-benzoquinone [98].

\subsubsection{Transamination reaction}

A particularly efficient and simple synthesis of $\mathrm{N}$-substituted DABQDI based on transamination was recently reported (Scheme 11) [100]. During the reaction pathway, TAB tetrachloride is deprotonated in presence of a primary alkylamine and oxidized under air to the corresponding quinone. The 
ammonium formed during the first step is crucial for the further generation of a charged iminium intermediate which yields product $\mathbf{4 0}$ via transamination. This atom-efficient method allowed to introduce various alkylamines without using any metal catalyst.

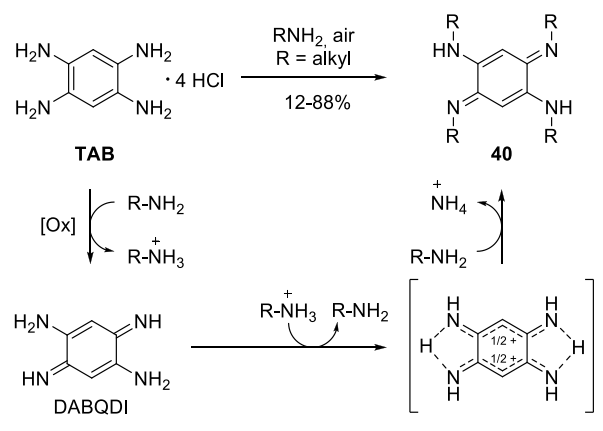

Scheme 11. N-substituted DABQDI via transamination [100].

\subsubsection{Methylation and aminomethylenation of TAB}

Eventually, the formation of charged DABQDI is conceivable by direct methylation or aminomethylenation of the TAB precursor. Staab and co-worked performed an Eschweiler-Clarke reaction in order to reach tetrakis(dimethylamino)benzene 43 incorporating four tertiary amines (Scheme 12) [101]. Following chemical or aerobic oxidation, the bis-cationic quinone $\mathbf{4 4}$ was isolated as a black-violet crystals ( $\lambda_{\max }=573 \mathrm{~nm}$ in acetonitrile). Analogous derivatives have more recently been obtained from the reaction of perfluorobenzene with various lithium dimethylamides to form $\mathbf{4 5}$, followed by protodefluorination to reach $\mathbf{4 3}$ [102].

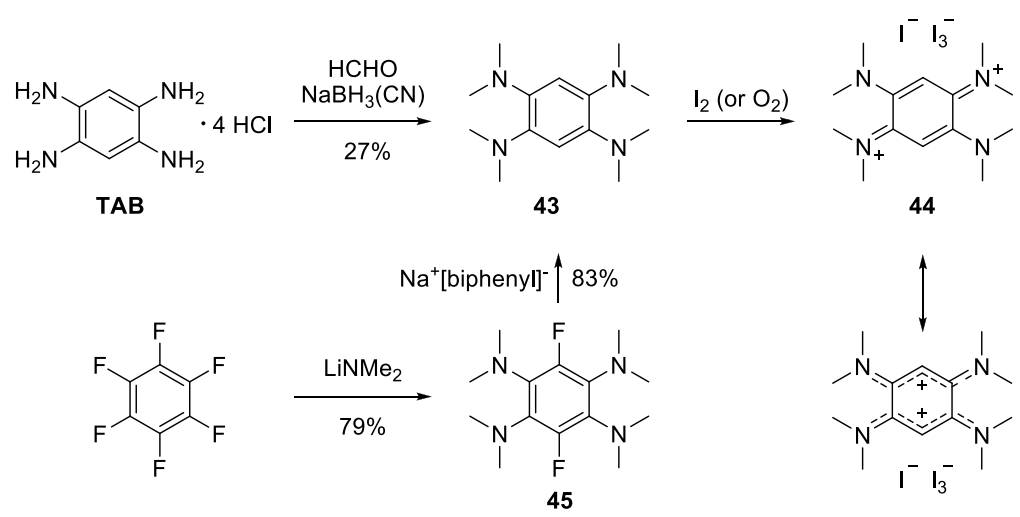

Scheme 12. Access to octamethyl-TAB and the corresponding diamino-benzoquinonediiminium salt [101, 102].

In a different way, Himmel et al. reported an original strategy to access tetrakis(tetramethylguanidino)benzene $\mathbf{4 6}$ by treatment of TAB with $N, N, N^{\prime}, N^{\prime}-$ tetramethylformamidinium chloride (Scheme 13) [103]. This relatively stable molecule was then oxidized by iodine to yield the corresponding purple charged quinone 47 ( $\lambda_{\max }$ ca. 350-470 nm in acetonitrile). 


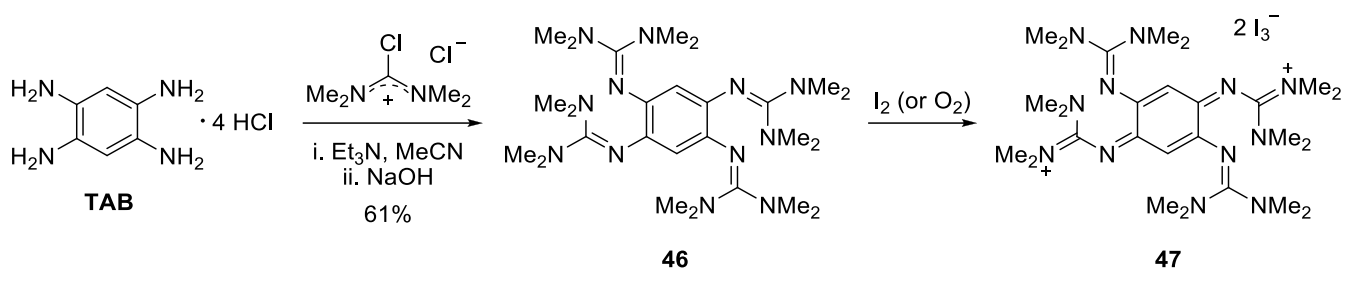

Scheme 13. Aminomethylenation of the TAB [103].

\subsubsection{Synthesis from benzothiadiazole}

Direct $C$-functionalization of DABQDI is so far unknown, however it is possible to access indirectly to these derivatives via a TAB precursor. Even if possibilities to access $C$-functionalized TAB remain scarce, few examples demonstrate a versatile approach based on the benzothiadiazole platform 48 [104-108]. This precursor is converted to the 4,7-dibromo-5,6-dinitrobenzothiadiazole 49 which can be coupled with a thiophene unit to from 50 (Scheme 14). The thiadiazole heterocycle and the nitro functions are finally reduced in the same step in presence of $\mathrm{Zn}$ and acetic acid. Because of its inherent unstability, compound $\mathbf{5 1}$ was directly condensed to diketone derivatives to access various quinoxaline dyes. However, we can reasonably expect its oxidation into $C$-substituted DABQDI $\mathbf{5 2}$ according to all the previous works on the oxidation of tetraaminobenzene derivatives.

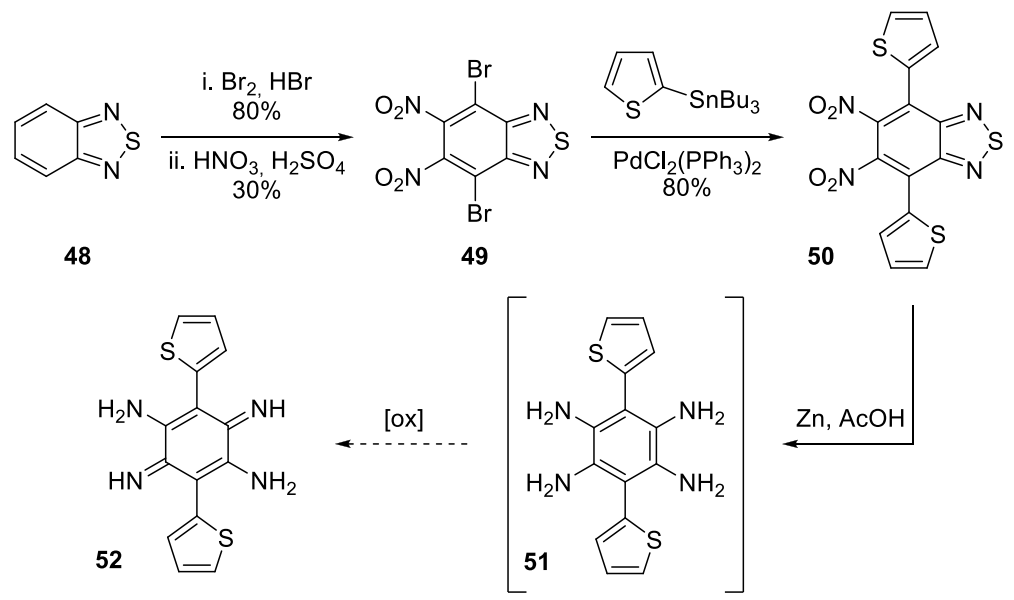

Scheme 14. Benzothiadiazole-based strategy to access $C$-functionalized TAB [104].

This hypothesis is consolidated by a recent work published in 2015 by Bunz et al. who reported a synthesis of ethynyl-functionalized DABQDI 56 based on two successive reductions of bisbenzothiadiazole 53 using $\mathrm{LiAlH}_{4}$ to yield 54 . A mixture of $\mathrm{LiAlH}_{4} / \mathrm{Cu}(4: 1)$ finally allows to reach quinone 56 , whose formation results probably from the aerobic oxidation of its tetraamine aromatic precursor 55 (not isolated) (Scheme 15) [109]. Such functionalized platform has been used for the convenient generation of various azaacenes by condensation with o-quinones. 


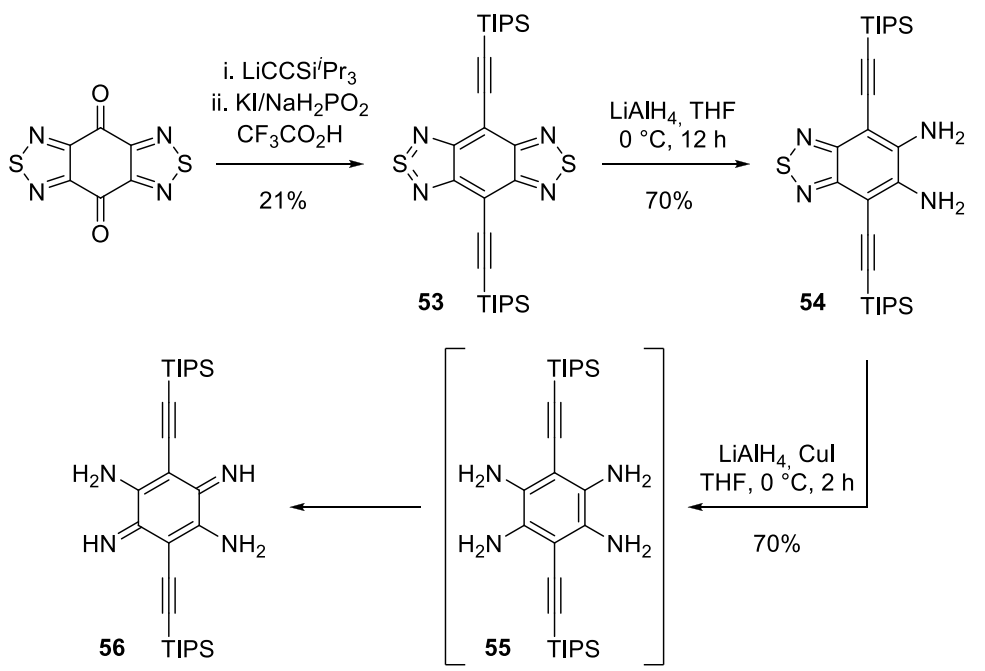

Scheme 15. Strategy to access ethynyl-functionalized DABQDI [109, 110].

It is noteworthy that strategies based on benzothiadiazole precursors to access a variety of $C$ functionalized DABQDI let foresee tremendous possibilities, especially in view of the numerous efficient methods reported for the functionalization of benzothiadiazoles [111, 112].

\subsection{Properties of DABQDI}

\subsubsection{Tautomerism}

It is well-established that the azophenine quinone and related DABQDI are subject to a doubleproton transfer involving two possible tautomers, as presented in Scheme 16. This fast exchange has been characterized in solution and at the solid state using ${ }^{1} \mathrm{H}$ and ${ }^{15} \mathrm{~N}$ NMR experiments [113]. Moreover, IR spectroscopy and theoretical calculations demonstrated that this isomerization could be triggered by UV-light irradiation [77].

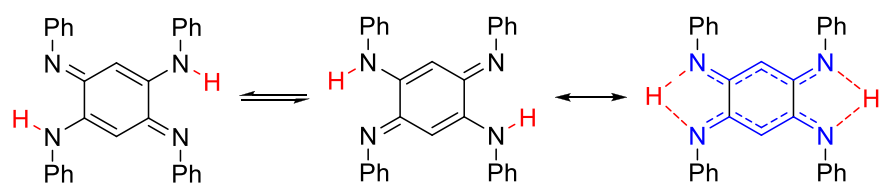

Scheme 16. Tautomeric equilibria of azophenine 27 in solution.

\subsubsection{Acidochromism}

In 1966, Dähne and Leupold predicted the so-called "coupling principle" in organic dyes to rationalize the unique spectroscopic properties of molecules incorporating $12 \pi$-electrons, that are best described as constituted of two $6 \pi$-subsystems chemically linked by two C-C single bonds but electronically independent [114]. Quinone 31a (Scheme 17) perfectly illustrates this principle as shown on its X-ray structure which clearly established the presence of two independent cationic trimethine cyanine motifs 
linked by two C-C single bonds [101]. Such model allows to explain the particularly red-shifted absorption of this relatively simple molecule. The hypothesis of a "coupling principle" was experimentally demonstrated by Braunstein et al., who investigated the acid-base properties of DABQDI 31a which can be successively protonated twice to form the corresponding mono and dication, $31 \mathrm{a} \cdot \mathrm{H}^{+}$and $\mathbf{3 1} \mathbf{a} \cdot \mathbf{2} \mathrm{H}^{+}$ respectively, featuring two independent $6 \pi$-electrons systems on the same unsaturated cycle [93, 115]. $\mathrm{X}$-ray analysis of crystals of monoprotonated specie $31 \mathrm{a} \cdot \mathrm{H}^{+}$reveals the absence of bond length alternation between the nitrogen atoms of the trimethine unit (in the "upper part" of the molecule) whereas an alternation of single and double bonds could be observed between the nitrogen atoms of the lower part of the molecule. As expected, $\mathrm{X}$-ray diffraction study of the diprotonated species $\mathbf{3 1 a \cdot 2 \mathbf { H } ^ { + }}$ revealed a full delocalization of the each $6 \pi$-subunits and the absence of conjugation between the two halves of the dyes. The red-shift of absorption measured in methanol/water solution going from 31a $\left(\lambda_{\max }=426 \mathrm{~nm}\right)$ to $31 \mathrm{a} \cdot \mathrm{H}^{+}\left(\lambda_{\max }=527 \mathrm{~nm}\right)$ and to $31 \mathrm{a} \cdot 2 \mathrm{H}^{+}\left(\lambda_{\max }=564 \mathrm{~nm}\right)$ is attributed to the $\Pi \rightarrow \pi^{*}$ intraquinone transition. Thus, this remarkable behavior is a rare example of acidochromy for which it is possible to control the degree of delocalization of two different $\pi$-subsystems in a single molecule depending on the $\mathrm{pH}$. It is noteworthy that fluorescence is detectable for neutral quinone $\mathbf{3 1}$ when $\mathrm{R}=$ $\mathrm{Ph}\left(\lambda_{\mathrm{em}}=480 \mathrm{~nm}\right)$ and is dramatically quenched upon protonation of the system [115].
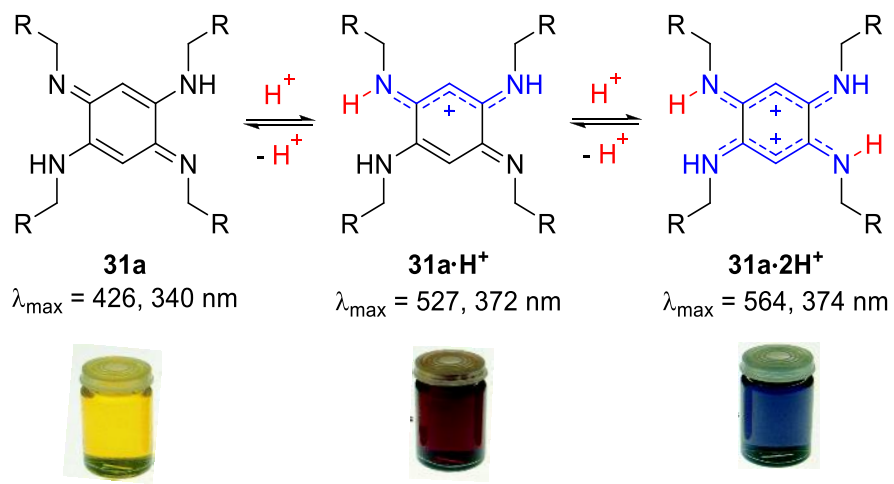

Scheme 17. Illustration of the coupling principle in 12-m electrons quinone 31a (localized vs delocalized distribution upon protonation evidenced from X-ray analyses) and corresponding coloration in $\mathrm{CH}_{2} \mathrm{Cl}_{2}$ solution $\left(\mathrm{R}={ }^{ } \mathrm{Bu}\right)$ [93].

\subsubsection{Redox properties}

The deprotonation of DABQI ligand generally occurs during the formation of coordination complexes (see Section 4), generating $D A B Q D I^{2-}$ in which the two negative charges can be symmetrically delocalized between the trimethine units. This dianion can undergo two consecutive one-electron reductions to afford radical DABQDI3-• then tetraanion DABQDI4- (Scheme 18). Consequently, these redox possibilities offers the opportunity to stabilize diamagnetic or paramagnetic species using this bridging ligand. 


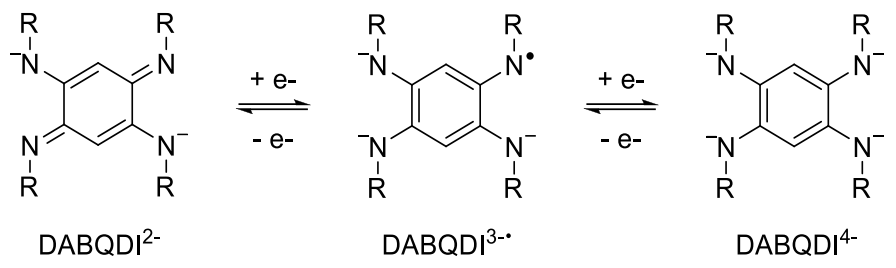

Scheme 18. Redox states of the deprotonated DABQDI ligand (adapted from ref. [116]).

In 2005, the redox versatility of DABQDI was further illustrated by oxidation of quinone $\mathbf{3 1}$ by AgOTf which lead to the formation of a red filtrate [117]. After electrochemical investigations, it turned out that following one-electron oxidation, two competitive pathways from $31^{+\bullet}$ tends to the generation dimer $\mathbf{3 2}$, as the first example of reversible $\mathrm{C}-\mathrm{C}$ coupling without dehydrogenation of a quinone derivative (Scheme 19).

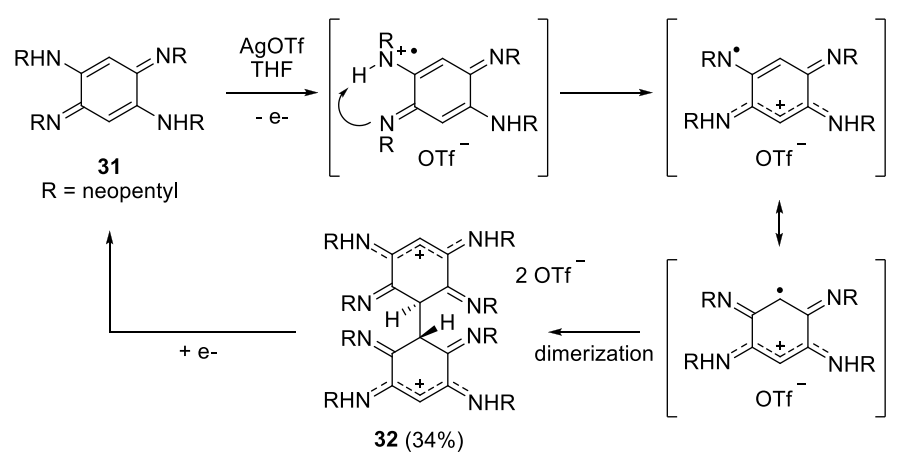

Scheme 19. Reversible dimerization of DABQDI [117].

\section{Coordination chemistry of 2,5-diamino-para-benzoquinonediimines}

\subsection{Unsubstituted DABQDI ligand}

Although 1,4-dihydroxybenzoquinone (DHBQ) is probably the most used quinoid ligand (more than 200 complexes based on mono-, dinuclear compounds, and polymers) [8], its stepwise metalation leading to dinuclear and oligomeric complexes has not been described to date. Surprisingly, the corresponding nitrogenated ligand DABQDI has been much less investigated since only two articles by Lever et al. in in 1993 and 2000, reported its use as ligand [68, 118]. In both cases, the DABQDI was prepared in situ in order to overcome its difficult isolation in good yield. Although the ruthenium complex 57 (Scheme 20) reported in 1993 was only characterized by NMR spectroscopy, this compound is - to the best of our knowledge - the first example of use of the unsubstituted 2,5-diamino- $p$ benzoquinonediimine (DABQDI) as ligand. In presence of base, TAB tetrachloride was converted into $D A B Q D I$, for which coordination to ruthenium was accompanied by an isomerization to the corresponding ortho-quinone. Complex 57 displays a weak low energy absorption band at $641 \mathrm{~nm}$,

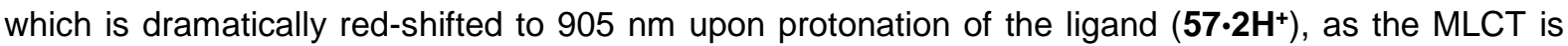
reinforced. 


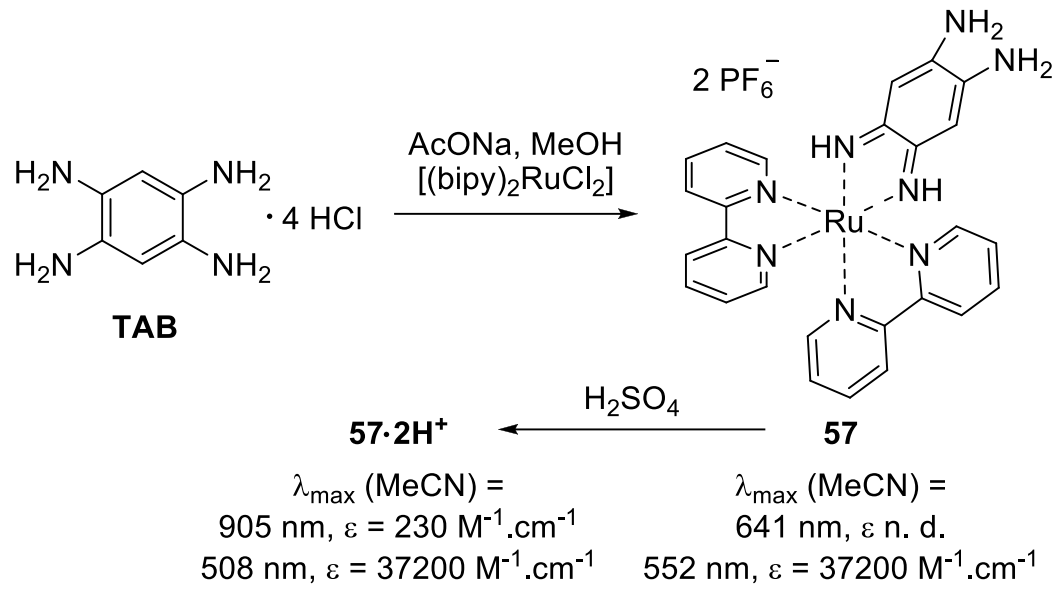

Scheme 20. Structure of $\mathrm{Ru}(\mathrm{II})$ complexes introducing an unsubstituted DABQDI ligand [68].

Upon treatment of TAB with $\left[\mathrm{Ru}(\text { bipy })_{2}(\mathrm{MeOH})_{2}\right]^{2+}$ (in presence of oxygen and water), the formation of a dinuclear $\mathrm{Ru}(\mathrm{II})$ complex 58 could be observed (Scheme 21) [118]. Surprisingly, during the course of the reaction, the expected bridging DABQDI ligand was converted to 1,2,4,5-tetraimino-3,6diketocyclohexane, following a 1,4-Michael addition of two hydroxide molecules on an intermediate binuclear specie.

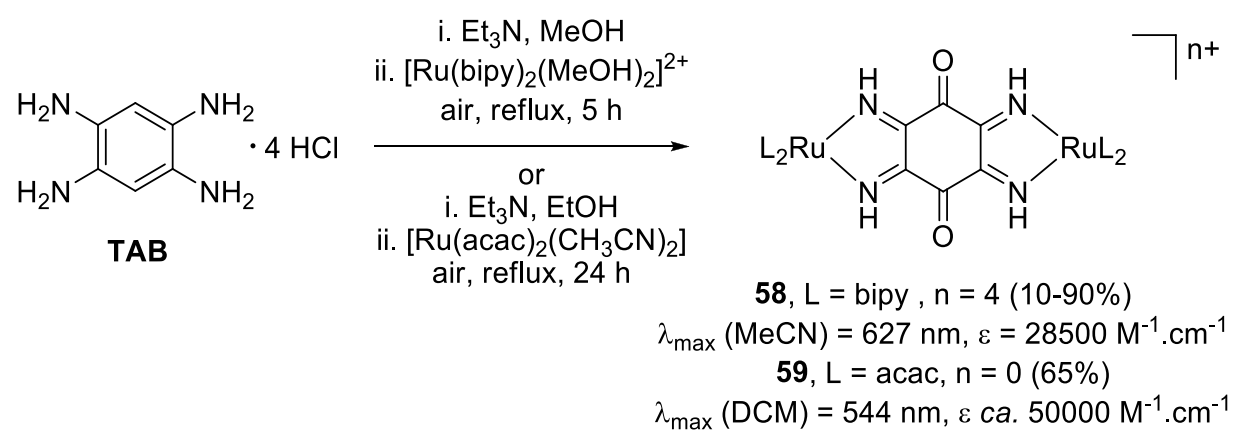

Scheme 21. Dinuclear Ru(II) complexes of 1,2,4,5-tetraimino-3,6-diketocyclohexane (bipy =2,2'-bipyridine; acac = acetylacetonate) $[118,119]$.

The complex $\mathbf{5 8}$ exhibits strong absorption in the red region which is easily tune by electrochemical reduction of the ligand. Calculations and spectroelectrochemical measurements revealed a nonnegligible mixing of the ruthenium orbitals through the bridging ligand, which increased upon reduction of the complex 58 to $+3\left(\lambda_{\max }=1176,810 \mathrm{~nm}\right)$ and $+2\left(\lambda_{\max }=758 \mathrm{~nm}\right)$ oxidation states (Figure 6). 


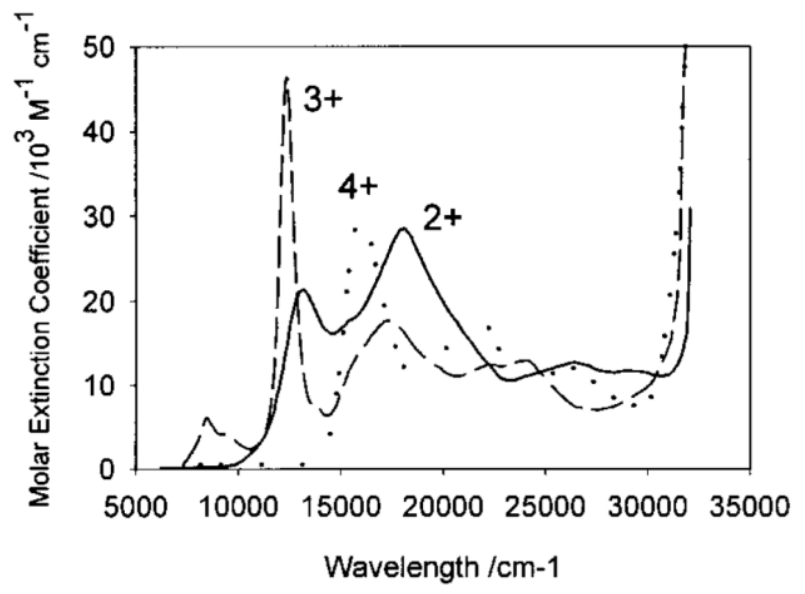

Figure 6. Absorption spectra of complex 58 and reduced forms (ca. 6.10-5 $\mathrm{M}$ ) in acetonitrile containing $0.3 \mathrm{M}$ $\mathrm{Bu}_{4} \mathrm{NPF}_{6}$. Solid line: $\mathrm{E}=-0.27 \mathrm{~V}$. Short-dashed line: $\mathrm{E}=0.1 \mathrm{~V}$. Long-dashed line: $\mathrm{E}=0.55 \mathrm{~V}$ (potentials vs SCE). Reprinted with permission from Ref. [118]. Copyright 2000 American Chemical Society.

Lately, complex 59 featuring acetylacetonate ancillary ligands instead of bipyridines was prepared and shows intense and narrow absorption at $544 \mathrm{~nm}$, assigned to a MLCT transition [119]. Compared to bipyridine, the acetylacetonate ligands favor the two consecutive metal-centered oxidations of $\mathbf{5 9}$ to the dicationic species $59^{2+}$, which displays ca. $670 \mathrm{~nm}$. Upon oxidation to $59^{+}$, moderate mixed valence character implying $\mathrm{Ru}(\mathrm{II}) / \mathrm{Ru}(\mathrm{III})$ centers was identified by EPR (Figure 7), with $g$ component splitting matching a lower $\mathrm{Ru}(\mathrm{III})$ species ( $4 \mathrm{~d}^{5}$ configuration), but however with no observation of IVCT band in the NIR. In contrast, upon reduction to $59^{-}$, the MLCT transition is shifted to $628 \mathrm{~nm}$ and a weak band is noticed ca. $1040 \mathrm{~nm}\left(\varepsilon=2200 \mathrm{M}^{-1} \cdot \mathrm{cm}^{-1}\right)$, which, combined with EPR experiments showing broad signals at 298 and $110 \mathrm{~K}$, suggests mixed orbital contributions from ligand and metal centers.

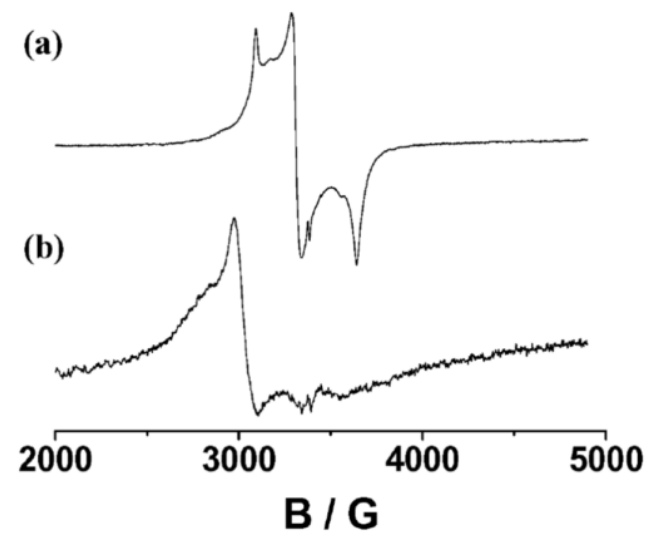

Figure 7. EPR spectra of (a) $59^{-}$and (b) $59^{+}$in dichloromethane $\left(0.1 \mathrm{M} \mathrm{Bu}_{4} \mathrm{NPF}_{6}\right)$ at $110 \mathrm{~K}$ with microwave frequencies of 9.4745 (a) and $9.4729 \mathrm{GHz}$ (b), respectively. Reproduced from Ref. [119] with permission from The Royal Society of Chemistry.

So far, only one report deals with the direct metalation of unsubstituted DABQDI ligand that could successfully be isolated in a large scale in 2014 [78]. In presence of $\mathrm{Ni}(\mathrm{acac})_{2}$, its metalation reaction easily form planar Ni-DABQDI tapes 60 which length depends on the solvent used for the reaction, the precipitation of the complex being the factor limiting the oligomerization process (Scheme 22). 


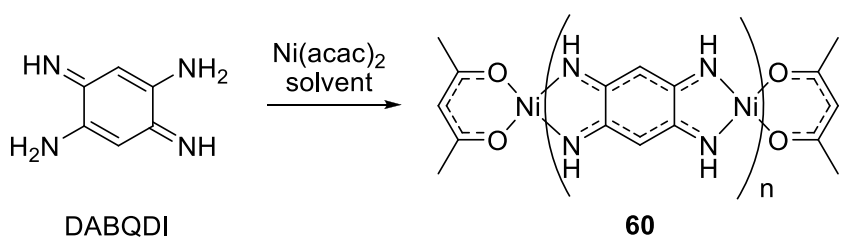

$\mathrm{n}=1(\mathrm{PhMe}), 2$ (THF), 3 or 4 (DMSO)

Scheme 22. Synthesis of $\mathrm{Ni}$ tapes of different lengths depending on the solvent (acac = acetylacetonate) [78].

Importantly, although theses complexes can be viewed as "extendable" since each oligomer can evolve in solution and rearrange into a longer form, they are also stable (that is, much more inert with respect to the oligomerization) depending on the solvent. In $\mathrm{N}, \mathrm{N}$-dimethylsulfoxide, the tetramer (i.e. the pentanuclear species) displays a broad absorption spamming from the UV up to $900 \mathrm{~nm}$, in the NIR region (Figure 8). TD-DFT calculations pointed out that the red-shift which accompanied the oligomerization was mainly due to a very efficient extension of the effective conjugation pathway (Figure 8).
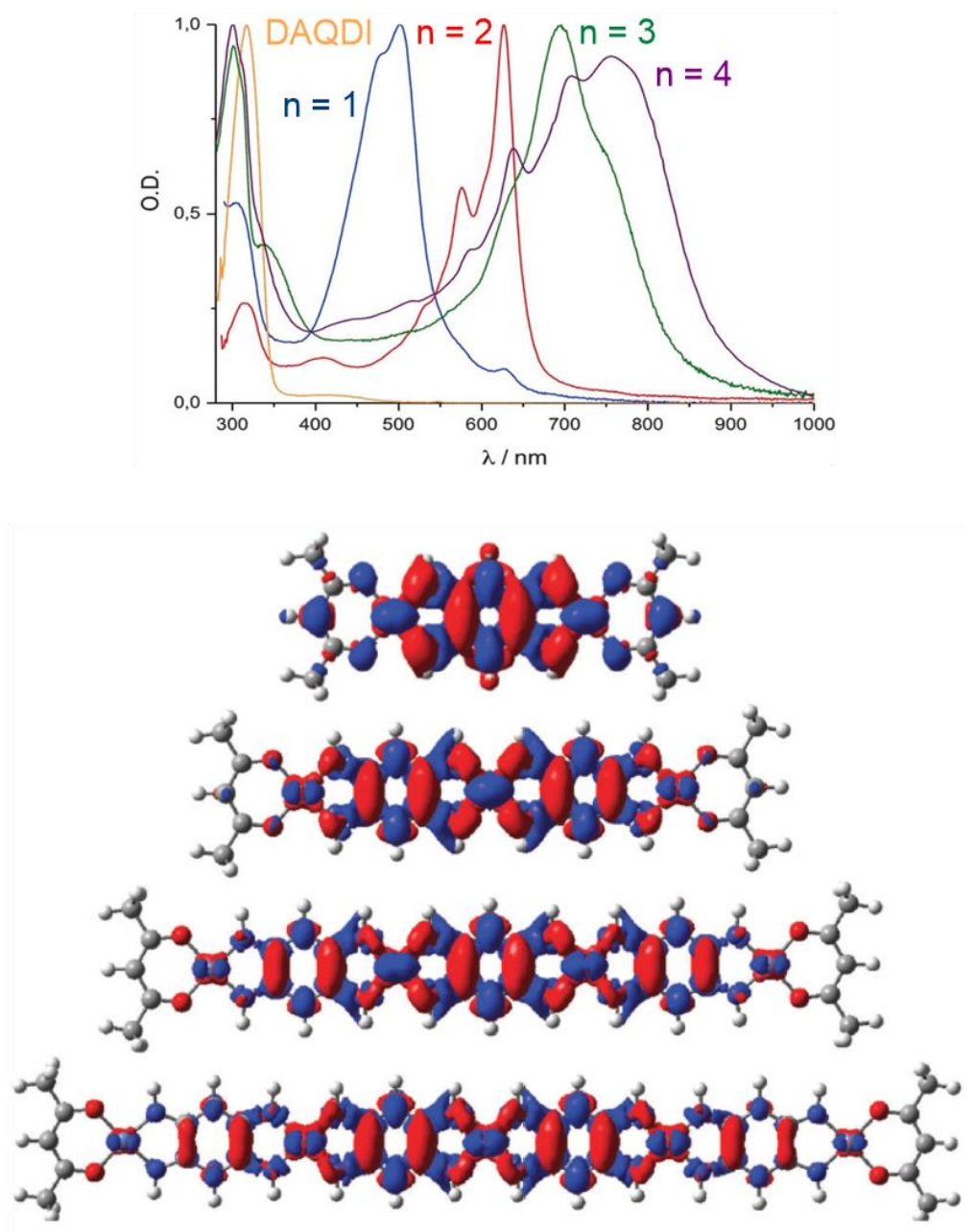

Figure 8. Absorption spectra (top) and M06/6-31G(d) delta density plots (bottom) between the excited and ground states for Ni tapes 60 of different lengths. Red (blue) regions indicate increase (decrease) of the density upon absorption [78]. Reproduced by permission of The Royal Society of Chemistry. 


\section{2. $N$-substituted DABQDI ligand}

Complexes based on $C$-substituted QDIs are hitherto unknown but it is relevant to mention that $\mathrm{N}$ substituted DABQDI ligands have attracted much more interest compared to unsubstituted DABQDI, as their easy access and high solubility paved the way to their use in the preparation of mononuclear and dinuclear complexes.

\subsubsection{Mononuclear complexes}

Kaim and co-worker reported in 1998 that the treatment of azophenine with one or two equivalents of $\left[\mathrm{Cu}\left(\mathrm{PPh}_{3}\right)_{4}\right]\left[\mathrm{BF}_{4}\right]$ leads in both cases to the formation of a mononuclear complex 61 (Chart 4) [120]. After crystallization of the specie, it was first observed that the original 1,4-quinone isomerized to a 1,2quinone during chelation to $\mathrm{Cu}(\mathrm{I})$. A second interesting feature was the presence of an interaction between a fluorine atom of the $\mathrm{BF}_{4}$ ion and the pendant $\mathrm{N}-\mathrm{H}$ hydrogens of the o-diamine part of the ligand, thus explaining the stability of the complex. A metal-induced tautomerism was also evidenced to take place during the coordination of azophenine to $\left[\operatorname{Re}(\mathrm{CO})_{5} \mathrm{Cl}\right]$ complex [121]. In this instance, additional stabilization of the mononuclear complex 62 was brought in the solid state by $\mathrm{Cl} \cdots \mathrm{H}$ interactions between the $\mathrm{N}-\mathrm{H}$ hydrogens of the ortho-diamino motif and the chlorine atom of a neighbor complex. UV-Vis absorption of the copper (61) and rhenium (62) complexes shows broad absorptions spamming from the UV up to $700 \mathrm{~nm}$ with high extinction coefficients and the low energy bands were attributed to MLCT transitions. Interestingly, tungsten analogs 63a-b reported by Braunstein et al. in 2004 revealed no need of stabilization by $\mathrm{H}$-bonding interactions. These $\mathrm{W}(0)$ complexes display absorption centered in the red region and allow to evidence a possible tuning of the absorption maxima by variation of the nitrogen substituents [122]. More recently, reaction of the DABQDI ligand with $\mathrm{Ni}\left(\mathrm{ClO}_{4}\right)_{2}$ hexahydrate in $\mathrm{DCM}$ provided the $\Delta$ and $\Lambda$ enantiomers of mononuclear complex 64 , the $\mathrm{Ni}(\mathrm{II})$ center adopting a distorted octahedral geometry. The bond length analysis disclosed the new electronic distribution within the 4,5-diamino-o-BQDI ligand, which implies that metal-induced tautomerism occurs during formation of the complex [123]. 
<smiles>FC(F)C(F)[InH]c1ccccc1</smiles>

61

$\lambda_{\max }(\mathrm{DCM})=525 \mathrm{~nm}$

$\varepsilon=12500 \mathrm{M}^{-1} \cdot \mathrm{cm}^{-1}$

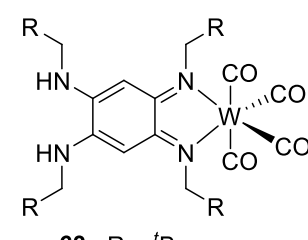

63a $R={ }^{t} \mathrm{Bu}$

$\lambda_{\max }(\mathrm{DCM})=607 \mathrm{~nm}$

$\varepsilon=30080 \mathrm{M}^{-1} \cdot \mathrm{cm}^{-1}$

63b $\mathrm{R}=\mathrm{Ph}$

$\lambda_{\max }(\mathrm{DCM})=620 \mathrm{~nm}$

$\varepsilon=26500 \mathrm{M}^{-1} \cdot \mathrm{cm}^{-1}$

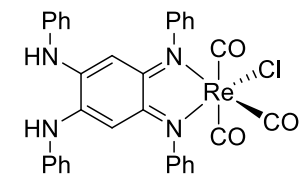

62

$\lambda_{\max }(\mathrm{DCM})=567 \mathrm{~nm}$

$\varepsilon=20100 \mathrm{M}^{-1} \cdot \mathrm{cm}^{-1}$

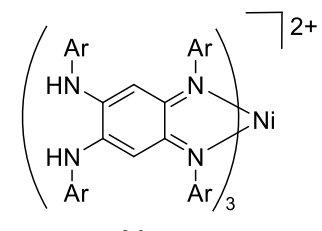

64

$\lambda_{\max }(\mathrm{DCM})=465 \mathrm{~nm}$

$\varepsilon=47900 \mathrm{M}^{-1} \cdot \mathrm{cm}^{-1}$

Chart 4. Monometallic complexes introducing an isomerized 4,5-diamino-o-BQDI [120-123].

\subsubsection{Dinuclear complexes}

\subsubsection{Dinuclear complexes from aromatic $T A B$}

The first attempts to generate dinuclear complexes resulted from deprotonation and oxidation of $\mathrm{N}$ substituted tetramethylsulfonyl-1,2,4,5-tetraaminobenzene ligand 65, described by Peng et al. in 1992 [124]. Interestingly, the $\mathrm{X}$-ray structures of the dinuclear $\mathrm{Cu}(\mathrm{I})$ complex $66 \mathbf{a}$ exhibited non-alternant bond lengths within the $\mathrm{N}-\mathrm{C} 1-\mathrm{C} 2-\mathrm{C} 3-\mathrm{N}$ bridges and particularly long bonds between $\mathrm{C} 1-\mathrm{C} 1$ ' and $\mathrm{C} 3-\mathrm{C} 3$ ' (Scheme 23). These data confirmed that oxidation of the TAB precursor occurs during the coordination reaction, generating a non-aromatic DABQDI-type ligand.<smiles>CS(=O)(=O)Nc1cc(NS(C)(=O)=O)c(NS(C)(=O)=O)cc1NS(C)(=O)=O</smiles>

65

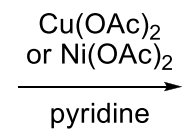

pyridine

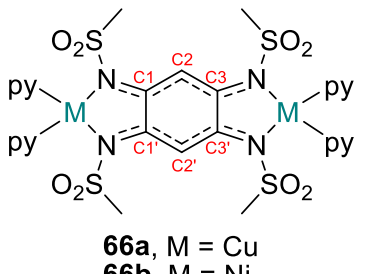

$66 \mathbf{b}, \mathrm{M}=\mathrm{Ni}$

Scheme 23. $\mathrm{Cu}(\mathrm{I})$ and $\mathrm{Ni}(\mathrm{II})$ complexes of $N, N^{\prime}, N^{\prime \prime}, N^{\prime \prime}$-tetramethylsulfonyl-DABQDI (py = pyridine) [124].

In their attempts to prepare new ditopic carbenes, Hahn et al. investigated the formation of $N$ heterocycles from a tetrasubstituted TAB [125]. While, on the one hand, the reaction of 69 with $\mathrm{Ge}\left[\mathrm{N}\left(\mathrm{SiMe}_{3}\right)_{2}\right]_{2}$ leads to the formation of the expected benzo bisgermylene complex $\mathbf{7 0}$, the reaction with $\mathrm{Se}\left[\mathrm{N}\left(\mathrm{SiMe}_{3}\right)_{2}\right]_{2}$ in presence of oxygen triggered on the other hand the oxidation of the $\mathrm{TAB}$ to the corresponding DABQDI and the bisstannylene $\mathbf{7 1}$ was isolated as a red-purple compound (Scheme 24). Molecular structure of 71 displayed the typical bond lengths corresponding to a $6 \pi+6 \pi$ bridging DABQDI unit (vide supra) and assed the electronic delocalization within the stannylene heterocycles. 
(Se[N(SiMe $\left.)_{2}\right]_{2}$

$70(90 \%)$

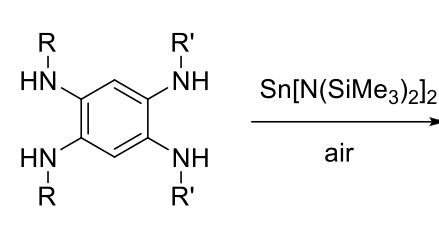

69

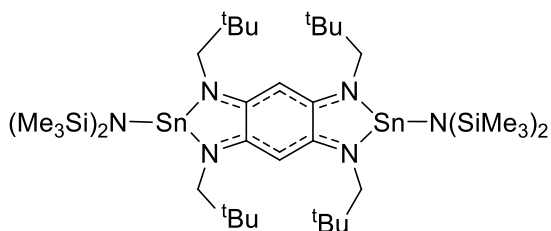

$71(67 \%)$

Scheme 24. Preparation of benzobisgermylene and quinobisstannylene [125].

Using their tetrakis(tetramethylguanidino)benzene precursor 47 (Scheme 13), Himmel and coworkers reported several examples of polynuclear complexes for which the bridging ligand adopted aromatic $(\mathrm{Zn}(\mathrm{II}), \mathrm{Cu}(\mathrm{I}), \mathrm{Pt}(\mathrm{II}))$ or quinoidal structures $(\mathrm{Cu}(\mathrm{II}))$ and properly characterized most of them by means of X-ray diffraction [126]. Among them, hexacationic complex 72 was identified in 2009 as the first example of dinuclear $\mathrm{Cu}$ (II) bridged by a tertiary amine-containing DABQDI derivative (Scheme 25). A antiferromagnetic coupling was evidenced between the two $\mathrm{Cu}$ (II) centers with $J=-35.4 \mathrm{~cm}^{-1}$. In a prolongation of these works, the authors demonstrated the possibility to prepare neutral, monocationic and dicationic (73) analogues by slight modifications of the reaction parameters [127]. In the case of 73, a weak antiferromagnetic coupling between the $\mathrm{Cu}(\mathrm{II})$ was evidenced. However, a strong ferromagnetic coupling was additionally measured between the radical cation bridging-ligand and the metallic extremities in the case of the cationic analogue.
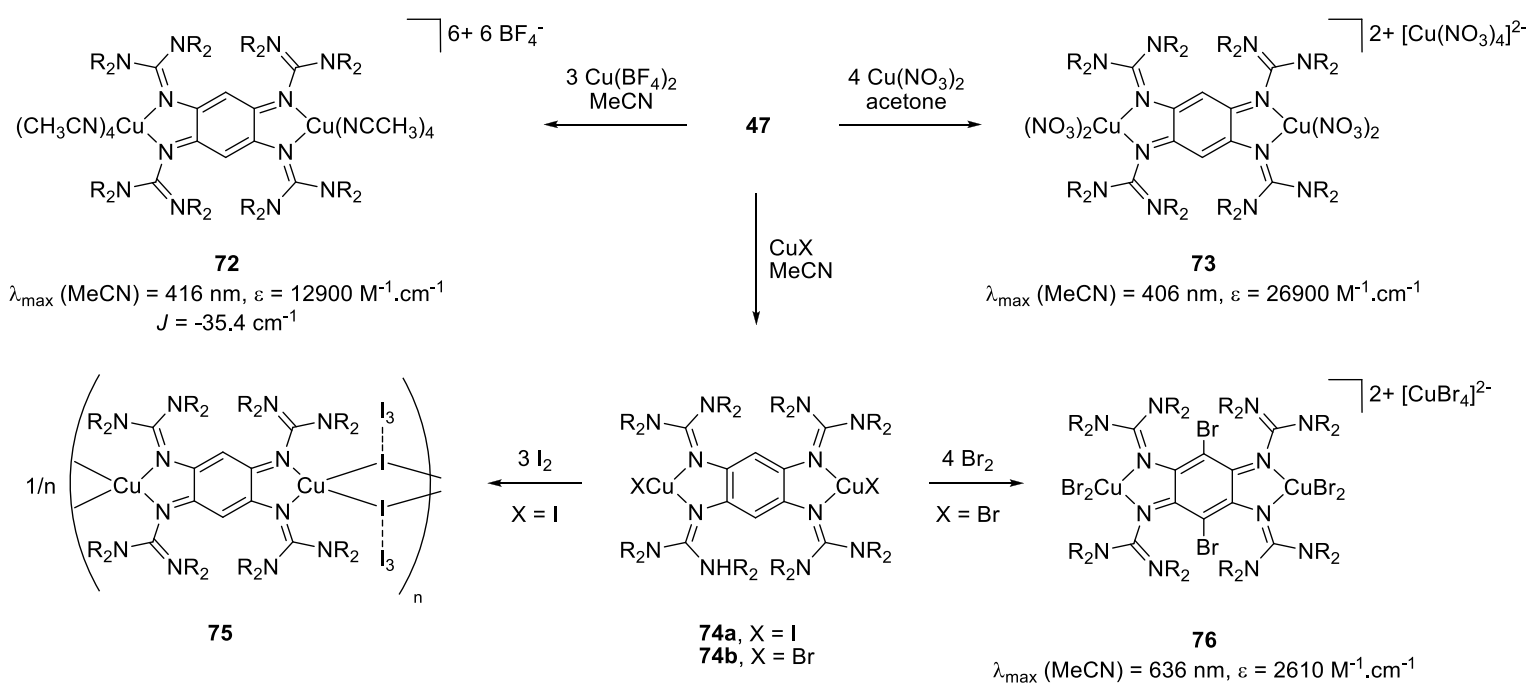

Scheme 25. Polynuclear complexes from a tetrakis(tetramethylguanidino)benzene precursor [126-128].

Starting from a $\mathrm{Cu}(\mathrm{I})$ complex bridged by an aromatic ligand (74a), oxidation in presence of iodine led to the formation of a polymeric complex 75 [128]. The authors suggested that the unusual structure of this polynuclear complex, notably the $\mathrm{Cu}(\mu \mathrm{l})_{2} \mathrm{Cu}$ unit, could be preferred because of $\mathrm{I} \cdots \mathrm{I}$ interaction. Semi-conductor properties have been evidenced for black polymer $\mathbf{7 5}$, with an estimated band gap of $1.05 \mathrm{eV}$. Interestingly, the treatment of $\mathbf{7 4 b}$ with bromine led to the oxidation of the complex to form the $\mathrm{Cu}(\mathrm{II})$ dinuclear specie $\mathbf{7 6}$ and the reaction was accompanied by a substitution of the central ligand with $\mathrm{Br}$ atoms. Thereafter, analogue of 75 has been developed starting from a 2,3,5,6tetrakis(tetramethylguanidino)pyridine [129]. Moreover, a green $\mathrm{Ag}(\mathrm{I})$ polymer obtained from $\mathbf{4 7}$ was identified as a semi-conductor with an estimated band gap ca. $3 \mathrm{eV}$ [130]. 


\subsubsection{Dinuclear complexes from $\mathbf{N}$-substituted DABQDI}

The first metalation reaction of $D A B Q D I$ affording the corresponding dinuclear complex was reported in 2000 by Braunstein and Siri [92]. A dinuclear Pt(II) complex incorporating a DABQDI bridging unit (78, Scheme 26) was obtained by reaction of 31a with 2 equivalents of $\left[\mathrm{PtCl}_{2}(\mathrm{COD})\right]$ in basic conditions. $\mathrm{X}$-ray analysis evidenced the square planar geometry of the metal centers and the bond length analysis revealed a totally delocalized $\pi$-structure between the two trimethine units, linked by two longer single C-C bonds ( $1.53 \AA$ ). Moreover, it also revealed an evolution of the cyclooctadienyl (COD) ligand during the course of the metalation reaction. Dicationic intermediate complex 77 (not isolated) underwent a deprotonation of the COD moiety in presence of trimethylamine, leading to 78 with both $\left(1,2-\eta^{2}-6-\sigma-\right.$ cycloocta-1,4-dienyl) ligands being $\sigma, \pi$-bonded to the metal centers [131]. The main absorption band of 78 centered at $504 \mathrm{~nm}$ is attributed to a MLCT transition, while a characteristic $\Pi \rightarrow \pi^{*}$ intraquinone CT is observed at $479 \mathrm{~nm}$.

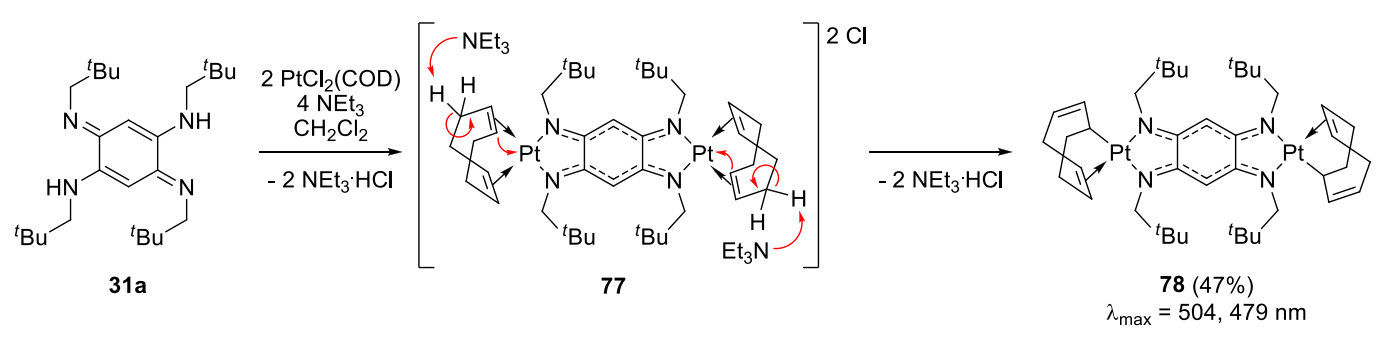

Scheme 26. Mechanism of formation of dinuclear Pt(II) complex [92, 131].

Metalation of DABQDI ligands with $\mathrm{M}(\mathrm{acac})_{2}$ could be also successfully carried out affording dinuclear species with metal centers and $\mathrm{N}$-substituents of different nature (Scheme 27). $\mathrm{Ni}(\mathrm{II})$ and $\mathrm{Pd}(\mathrm{II})$ complexes 79a-c and 80a-b exhibit similar electronic structures with two $6 \pi$-electron subsystems allowing a high delocalization between the two metals (see bond length on Figure 9) [131, 132]. The series 79a-d allows for a comparison of the influence of the $\mathrm{N}$-substituents on the electronic absorption of the $\mathrm{Ni}(\mathrm{II})$ complexes. A red-shift from 510 to $555 \mathrm{~nm}$ is observed going from neopentyl to phenyl substituents. However, this tendency is surprisingly not observed in the case of $\mathrm{Pd}(\mathrm{II})$ analogues $80 \mathrm{a}-$ b, these complexes showing absorption centered ca. $490 \mathrm{~nm}$. Cyclic voltammetry of 79a shows two reversible one electron oxidations at 0.05 and $0.91 \mathrm{~V} \mathrm{vs.} \mathrm{Fc}^{+} / \mathrm{Fc}$ and higher potentials for more electron poor $79 \mathrm{~b}$. Intriguingly, upon oxidation of 79a, appearance of two bands at 1030 and $910 \mathrm{~nm}$ was noticed [132]. Theoretical calculations pointed out that the oxidation was mainly related to the bridging quinone unit. However, in presence of additional pyridine, EPR analysis of $79 \mathrm{a}^{+}$at $4 \mathrm{~K}$ exhibited two broad signals ( $g=2.13$ and 4.16), which revealed a ferromagnetic coupling between $\mathrm{Ni}(\mathrm{III})$ and $\mathrm{Ni}(\mathrm{II})$ centers, the formed specie being therefore a mixed-valence complex of class III [133]. 

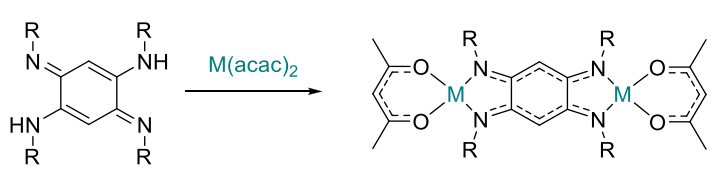

$\begin{array}{ll}\text { 79a, } M=\mathrm{Ni}, \mathrm{R}=\mathrm{CH}_{2}{ }^{\mathrm{t}} \mathrm{Bu}(55 \%) & \lambda_{\max }(\mathrm{DCM})=510 \mathrm{~nm}, \varepsilon=14800 \mathrm{M}^{-1} \cdot \mathrm{cm}^{-1} \\ \text { 79b, } \mathrm{M}=\mathrm{Ni}, \mathrm{R}=\mathrm{CH}_{2} \mathrm{Ph}(76 \%) & \lambda_{\max }(\mathrm{DCM})=519 \mathrm{~nm}, \varepsilon=34700 \mathrm{M}^{-1} \cdot \mathrm{cm}^{-1} \\ \mathbf{7 9 c}, \mathrm{M}=\mathrm{Ni}, \mathrm{R}=\mathrm{Ph}(82 \%) & \lambda_{\max }(\mathrm{DCM})=555 \mathrm{~nm}, \varepsilon=19500 \mathrm{M}^{-1} \cdot \mathrm{cm}^{-1} \\ \mathbf{7 9 d}, \mathrm{M}=\mathrm{Ni}, \mathrm{R}=p \text { - } \mathrm{Et}-\mathrm{Ph}(64 \%) & \lambda_{\max }(\mathrm{DCM})=559 \mathrm{~nm}, \varepsilon=52500 \mathrm{M}^{-1} \cdot \mathrm{cm}^{-1} \\ & \\ \mathbf{8 0 a}, \mathrm{M}=\mathrm{Pd}, \mathrm{R}=\mathrm{CH}_{2}{ }^{\mathrm{t} B u(55 \%)} & \lambda_{\max }(\mathrm{DCM})=491 \mathrm{~nm}, \varepsilon=66100 \mathrm{M}^{-1} \cdot \mathrm{cm}^{-1} \\ \mathbf{8 0 b}, \mathrm{M}=\mathrm{Pd}, \mathrm{R}=\mathrm{CH}_{2} \mathrm{Ph}(49 \%) & \lambda_{\max }(\mathrm{DCM})=488 \mathrm{~nm}, \varepsilon=10000 \mathrm{M}^{-1} \cdot \mathrm{cm}^{-1}\end{array}$

Scheme 27. Structure of dinuclear Ni(II) and Pd(II) complexes incorporating a DABQDI bridge [123, 131, 132].

It is worth mentioning that complex 79a has been evaluated as candidate pre-catalyst for the oligomerization of ethylene [131]. In presence of diethylaluminium chloride co-catalyst, the complex showed moderate activity but high selectivity for the production of $\mathrm{C}_{4}$ and $\mathrm{C}_{6}$ olefins. Afterwards, an azophenine $\mathrm{Ni}(\mathrm{acac})$ dinuclear complex has been successfully used as efficient catalyst for the polymerization of norbornene and methyl methacrylate [134]. In 2015, the dinuclear complex $79 d$ has been used for the polymerization of styrene and the engineering of the bulky $\mathrm{N}$-susbtituents provided efficient pre-catalysts [97].

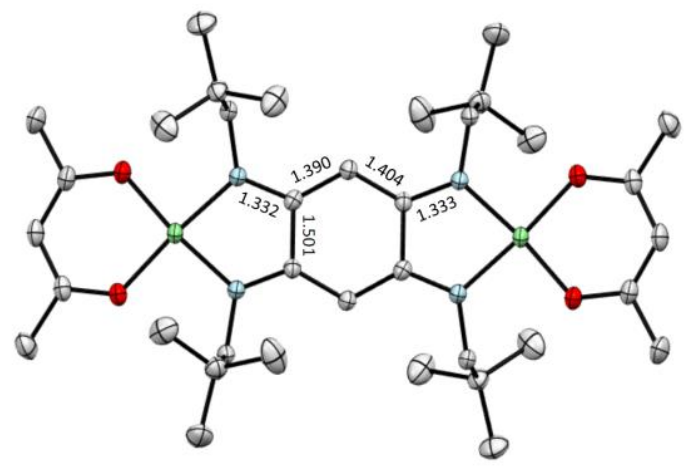

Figure 9. Structure and selected bond lengths $(\AA)$ of complex 79a [132]; Anisotropic displacement parameters at $50 \% ; \mathrm{H}$ atoms are omitted for clarity.

Works reported by Fujihara et al. described the preparation of the $\mathrm{B}(\mathrm{III})$ dinuclear complex $\mathbf{8 2}$ by deprotonation of the appropriate ligand 81 with butyllithium followed by chelation to $\mathrm{BF}_{3} \cdot \mathrm{OEt}_{2}$ (Chart 5 ) [123]. This complex exhibits bond order similar to the free diprotonated ligand (i.e. two independent $6 \pi-$ electron systems), with however an absorption located at the edge of the UV-Vis region ( $\lambda_{\max }=447$ $\mathrm{nm})$. The deprotonated ligand was mixed with $\left[\left(\operatorname{Ir}\left(\mathrm{Cp}^{*}\right) \mathrm{Cl}_{2}\right)_{2} \mathrm{Cl}_{2}\right]$ to prepare the first example of dinuclear Ir(III) complex bridged by a DABQDI ligand (83). This complex exhibits two highly delocalized m-electron subunits and an intense absorption in the same range that the $\mathrm{Ni}(\mathrm{II})$ analogue $79 \mathrm{~d}$ (Scheme 27). 


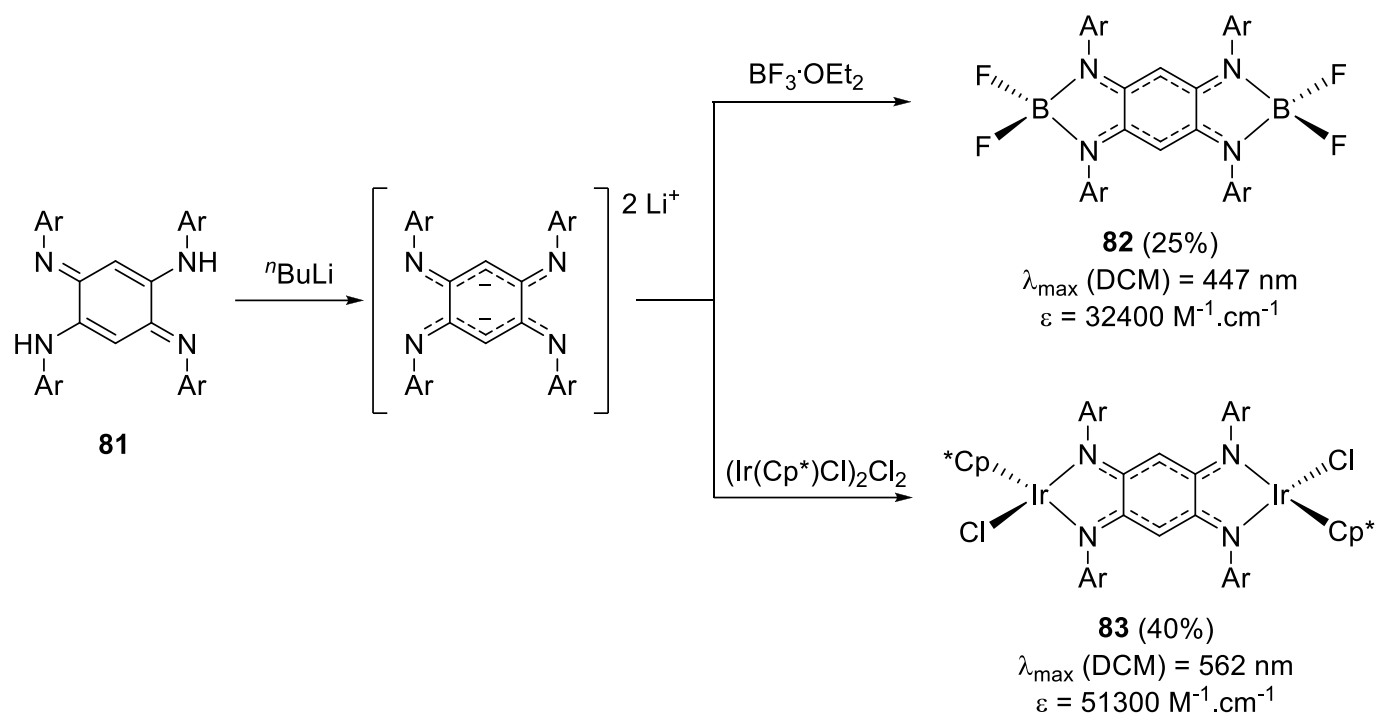

Chart 5. B(III) and Ir(III) complexes of DABQDI [123] ( $\mathrm{Ar}=p$-Et-Ph; $\mathrm{Cp}^{*}=$ pentamethylcyclopentadienyl).

Yang and collaborators reported in 2012 the first complexes of DABQDI chelated to alkali metals, 85-86, presented in Scheme 28 [135]. In presence of two equivalents of ${ }^{n} \mathrm{BuLi}$, quinone 84 yielded the dinuclear specie 85 , the two lithium atoms being distorted tetrahedral and slightly out of the plane of the two chelating nitrogen atoms. In contrast, the ligand underwent polymerization in presence of sodium in 1,2-dimethoxyethane. The structure of $\mathbf{8 6}$ displays similarities with its Li analogue, with two chemically linked $6 \pi$-electron subunits, but however, in this case, a higher coordination number of the alkali metal. Salt metathesis using $\mathrm{ZnCl}_{2}$ was efficiently performed on complex $\mathbf{8 5}$ and polymer $\mathbf{8 6}$ to afford the corresponding tetranuclear units $\mathbf{8 7}$ and $\mathbf{8 8}$, respectively. The authors mention the red to purple color changes for the compounds they characterized, but unfortunately this work does not give any information about the absorption or redox properties of these original complexes.

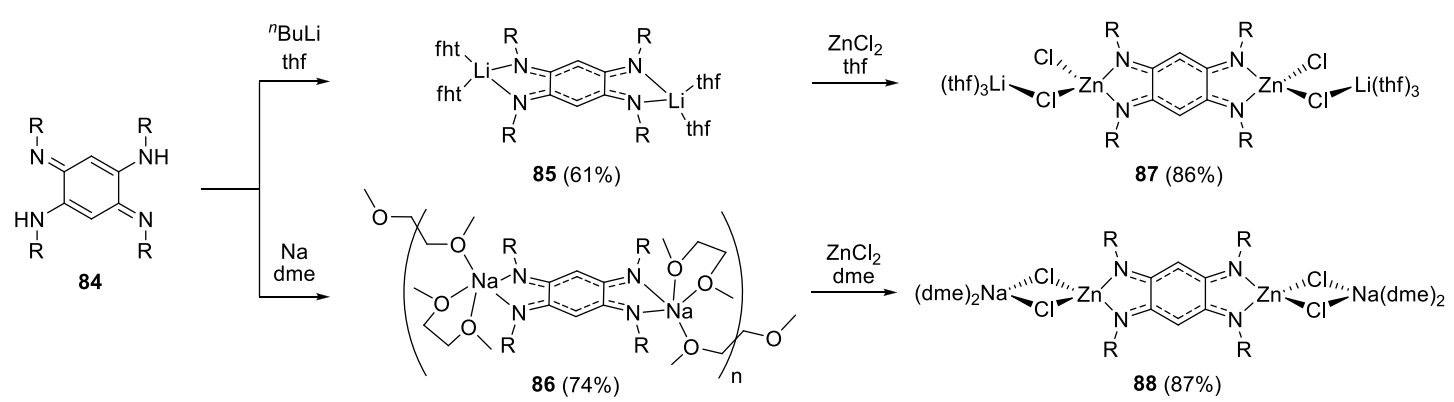

Scheme 28. Alkali metal-containing DABQDI complexes $\left(\mathrm{R}=2,{ }^{-}{ }^{-} \mathrm{Pr}_{2}-\mathrm{C}_{6} \mathrm{H}_{3}\right.$; thf $=$ tetrahydrofuran; dme $=1,2-$ dimethoxyethane) [135].

In 2013, Sarkar and co-workers reported a series of bridged dinuclear complexes of $\mathrm{Cu}$ (II) introducing deprotonated DHBQ [O,O,O,O], 2,5-dianilino-1,4-benzoquinone [O,NAr,O,NAr] or azophenine 27 [NPh,NPh,NPh,NPh] ligands to investigate their electrochemical and magnetic properties [136]. Interestingly, while the oxo-ligand-based complexes showed a distorted octahedral environment around the metal, the $\mathrm{Cu}(\mathrm{II})$ centres in derivative 89 (Figure 10) adopted distorted squarepyramidal coordination geometries. Susceptometry measurement using a superconducting quantum interference device (SQUID) revealed a high intramolecular coupling between the two copper atoms, 
with an isotropic exchange coupling constant $J=-23.2 \mathrm{~cm}^{-1}$. TD-DFT calculations pointed out that this larger value was mainly related to the superior polarizability and the elevated proportion of total spin density held by the $\mathrm{N}$ donor atoms of the ligand. A high exchange coupling constant is particularly relevant for the development of single molecule magnets since it guarantees a larger separation between spin ground and excited states, thus preventing fast relaxation of the magnetization [9].

The redox properties of $\mathbf{8 9}$ could not be screened because of the poor stability of the complex. However spectroelectrochemistry has been investigated in the case of a dinuclear Pt(II)-azophenine complex 3.35 featuring peripheral azobenzene ligands [137]. Complex 90 possesses an irreversible oxidation and three reversible reductions in THF which have a major influence on the electronic absorption (Figure 10). The neutral specie exhibits an absorption maximum at $619 \mathrm{~nm}$ which is redshifted to $770 \mathrm{~nm}$ upon one-electron reduction and accompanied by the appearance of a particularly broad band centred ca. $1870 \mathrm{~nm}$. Second and third reduction of 90 lead to a dramatic decrease of the lowest energy band and intense absorption at 1351 and $1191 \mathrm{~nm}$, respectively.

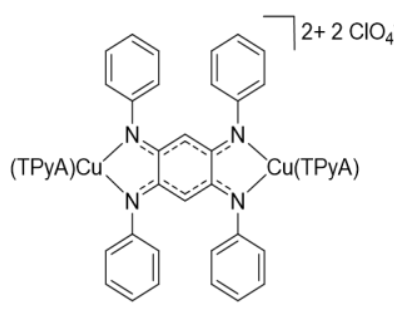

89

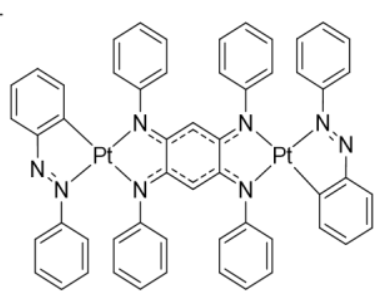

90

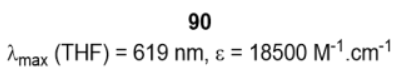

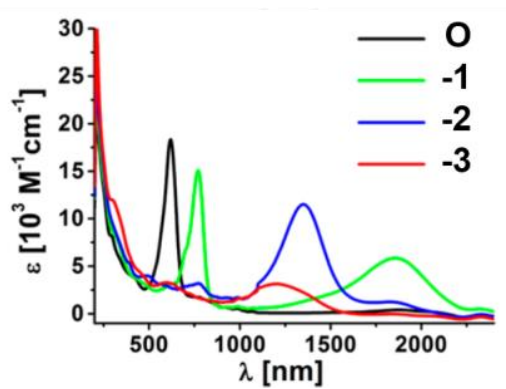

$\lambda[\mathrm{nm}]$

Figure 10. Azophenine-based dinuclear complexes 89-90 [136, 137] and absorption spectra of 90 under various redox states (TPyA $=$ tris(2-pyridylmethyl)amine). Reprinted with permission from ref. [137]. Copyright 2014 American Chemical Society.

In the continuity of the promising magnetic assets measured on $\mathbf{8 9}$, Harris and co-workers prepared and crystallized from azophenine the analogous dicationic complex 91 containing two $\mathrm{Fe}$ (II) centers and the corresponding reduced cationic species 92 (Figure 11) [116]. Analysis of the bond lengths of the ligand showed once again high conjugation within the $\mathrm{N}-\mathrm{C}-\mathrm{CH}-\mathrm{C}-\mathrm{N}$ fragments for both complexes, with a noticeable decrease of the N-Fe bonds length in the reduced specie, testifying of a stronger ligand-metal interaction. Mössbauer spectroscopy confirmed that the first reduction occurred on the deprotonated azophenine ligand, thus noted as DABQDI ${ }^{3-*}$, which explained its highest affinity for the $\mathrm{Fe}$ (II) centers. The investigation of the magnetic properties of 91 revealed a weak exchange coupling between the two ionic centers $\left(J=-2.90 \mathrm{~cm}^{-1}\right)$. However for the reduced specie 92, the $J$ constant was estimated to the order of $900 \mathrm{~cm}^{-1}$, a record value which attests of a strong antiferromagnetic exchange between the radical ligand and the iron atoms. 

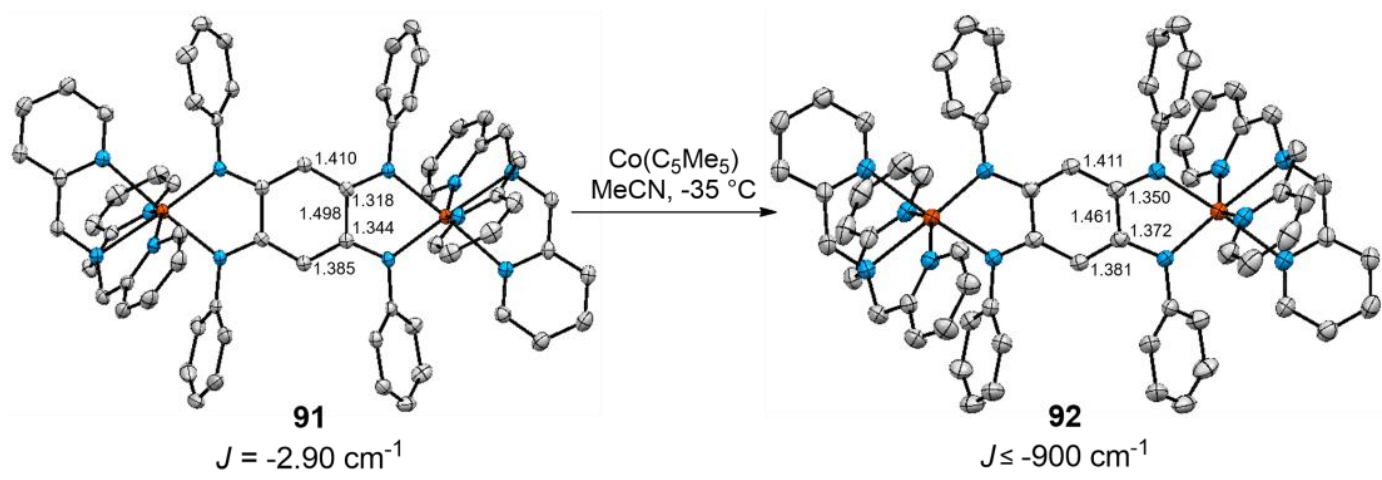

Figure 11. Structure and selected bond lengths $(\AA)$ of dinuclear Fe(II) complex 91 and its reduced form 92 [116]; Anisotropic displacement parameters at 50\%; $\mathrm{H}$ atoms and counter-ions are omitted for clarity.

Lately, Harris and collaborators repeated the study on a series of dinuclear complexes of $\mathrm{Cr}$ (III), $\mathrm{Mn}(\mathrm{II}), \mathrm{Fe}(\mathrm{II})$ and $\mathrm{Co}(\mathrm{II})$ and using a slightly bulkier tetramethyl azophenine derivative (L, Figure 12) [138]. The voltamogramms of the series are mainly characterized by one and three reversible oneelectron reductions for 94-96 and 93, respectively. The weak variation of reduction potentials, from $1.93 \mathrm{~V}(\mathbf{9 4})$ to $1.68 \mathrm{~V}(\mathbf{9 6})$ is consistent with an azophenine ligand-centered process. In the case of 93, azophenine reduction occurs at $-0.50 \mathrm{~V}$, and the two additional processes beyond $-1.50 \mathrm{~V}$ are attributed to $\mathrm{Cr}$ (III) reduction to $\mathrm{Cr}(\mathrm{II})$. Once the one-electron reduction occurred on the deprotonated ligand, impressive values of exchange coupling constants were determined, up to $-626 \mathrm{~cm}^{-1}$ for the $\operatorname{Cr}$ (II) complex 97. It is noteworthy that the steric bulk brought by the additional methyl on the phenyl rings is probably to account regarding the three-fold lower $J$ value for $99\left(J=-307 \mathrm{~cm}^{-1}\right)$ compared to 92 . The M-N bond distance between the ligand nitrogen and the metal within 93-96 can be linearly correlated

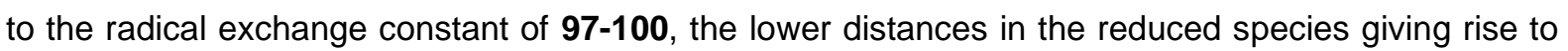
the higher $J$ values for the oxidized complexes. 

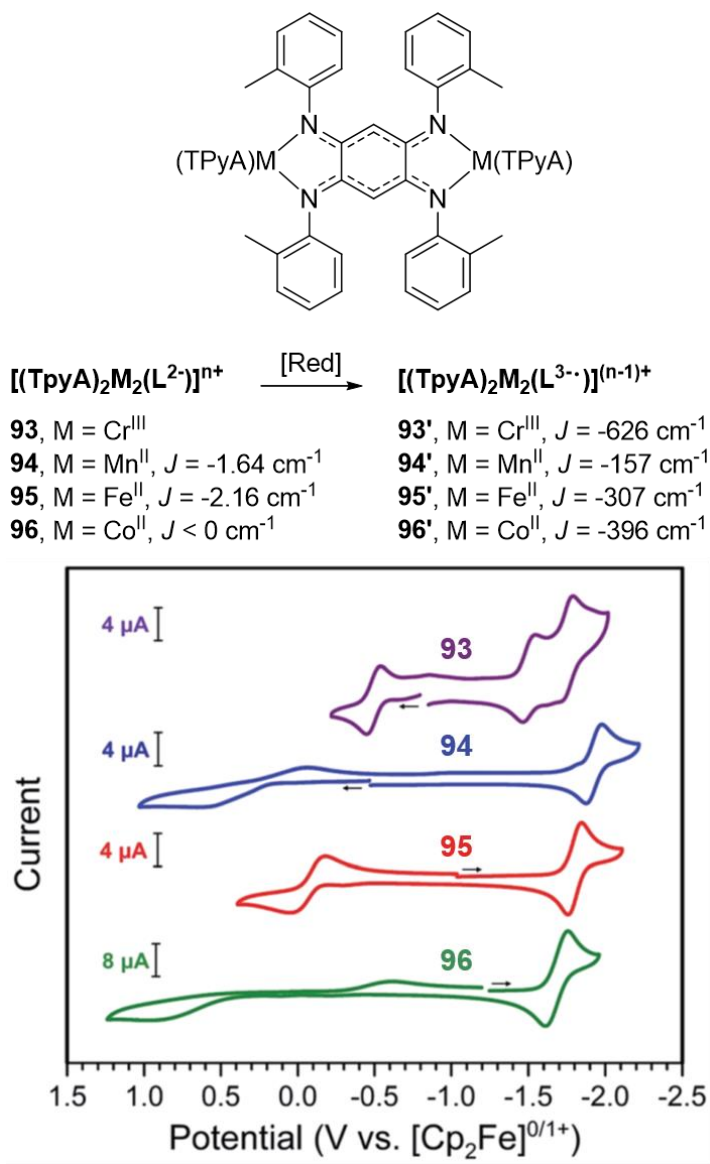

Figure 12. Efficient dinuclear single-molecule magnets developed by Harris et al. and cyclic voltammograms $(\mathrm{v}=$ $0.1{\mathrm{~V} . \mathrm{s}^{-1}}^{-1}$ for solutions of 93 (MeCN), 94 (THF), 95 (THF) and 96 (THF). Adapted from Ref. [138]. Published by The Royal Society of Chemistry.

\subsubsection{Tetranuclear complexes}

Siri, Braunstein and co-workers highlighted a drastic ancillary ligand effect that occurred by replacing the $\left[\mathrm{Pd}(\mathrm{acac})_{2}\right]$ reagent with $\left[\mathrm{Pd}(\mathrm{OAc})_{2}\right]$. Whereas the metalation of DABQDI 31a with $\left[\mathrm{Pd}(\mathrm{acac})_{2}\right]$ led to the formation of a dinuclear complex 80a (Scheme 27), the use of $\left[\mathrm{Pd}(\mathrm{OAc})_{2}\right]$ afforded instead a tetranuclear $\mathrm{Pd}(\mathrm{II})$ complex 101 (Figure 13) [139]. While NMR analysis revealed a high symmetry complex, X-ray diffraction allowed to conclude that the structure was highly stabilized by the ח-stacking of the two benzoquinone units $(3.80 \AA)$. The absorption of the tetranuclear species is characterized by a band centered at $428 \mathrm{~nm}$, which is blue-shifted compared to the dinuclear complex 80a $\left(\lambda_{\max }=491\right.$ $\mathrm{nm}$ ). Two successive one-electron oxidations lead to the $101^{+}$and $101^{2+}$ species (resp. 0.45 and 0.77 V vs. SCE), and a third oxidation was reached at higher potentials ( $1.50 \mathrm{~V}$ vs. SCE). Unfortunately, the fourth oxidation of the dimer could not be observed due to the oxidation of the electrolyte. 

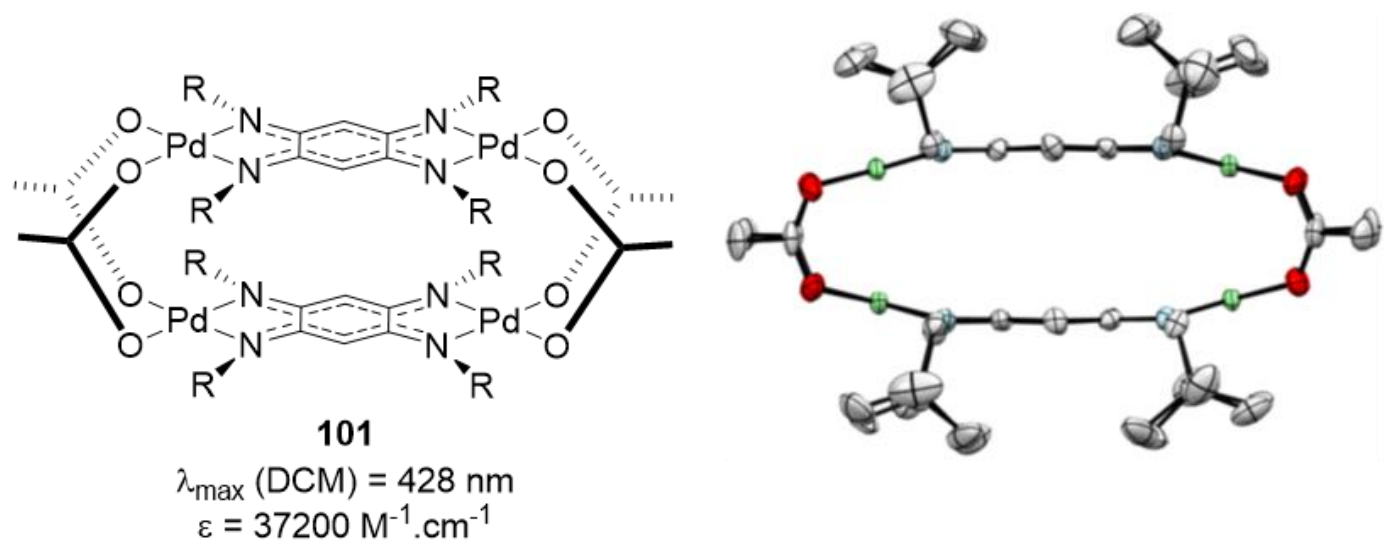

Figure 13. Tetranuclear $\mathrm{Pd}(\mathrm{II})$ complex 101 and side-view of its structure $\left(\mathrm{R}=\mathrm{CH}_{2} \mathrm{Bu}^{\mathrm{B}}\right.$ [139]; Anisotropic displacement parameters at $50 \%$.

\section{Conclusion}

2,5-diamino-1,4-benzoquinonediimines (DABQDI) can be considered as an emerging class of promising ligands in coordination chemistry whereas their first preparation was reported more than a century ago (Figure 14). The first member - $\mathrm{N}$-substituted with phenyl groups (azophenine) - was discovered by Kimich in 1875 through self-condensation of aniline. Few years later (1887), the unsubstituted parent molecule was reported by Nietzki when he observed the unstability of 1,2,4,5tetraaminobenzene (TAB) under air. Then, this type of $\mathrm{N}_{4}$ ligands was (surprisingly) not investigated during more than a century, whereas its oxygenated analogue $\mathrm{O}_{4}$ was the object of numerous studies in coordination chemistry. If Lever et al. mentioned the possible isomerization of DABQDI upon metalation in 1993, Kaim et al. was the first to fully characterize a (mononuclear) complex in 1998. From 2000, year in which Braunstein published the first $\mathrm{N}$-alkylated ligand and its dinuclear complex [Pt(II)], the coordination chemistry of these $\mathrm{N}$-substituted ligands attracted the interest of a large scientific community for the synthesis of complexes with unusual properties ( $M=\mathrm{Ru}, \mathrm{Fe}, \mathrm{Cu}, \mathrm{Pd}, \mathrm{Ni}, \mathrm{Zn}, \mathrm{Ir}, \mathrm{Sn}$, W, Re, Na, Li, B).

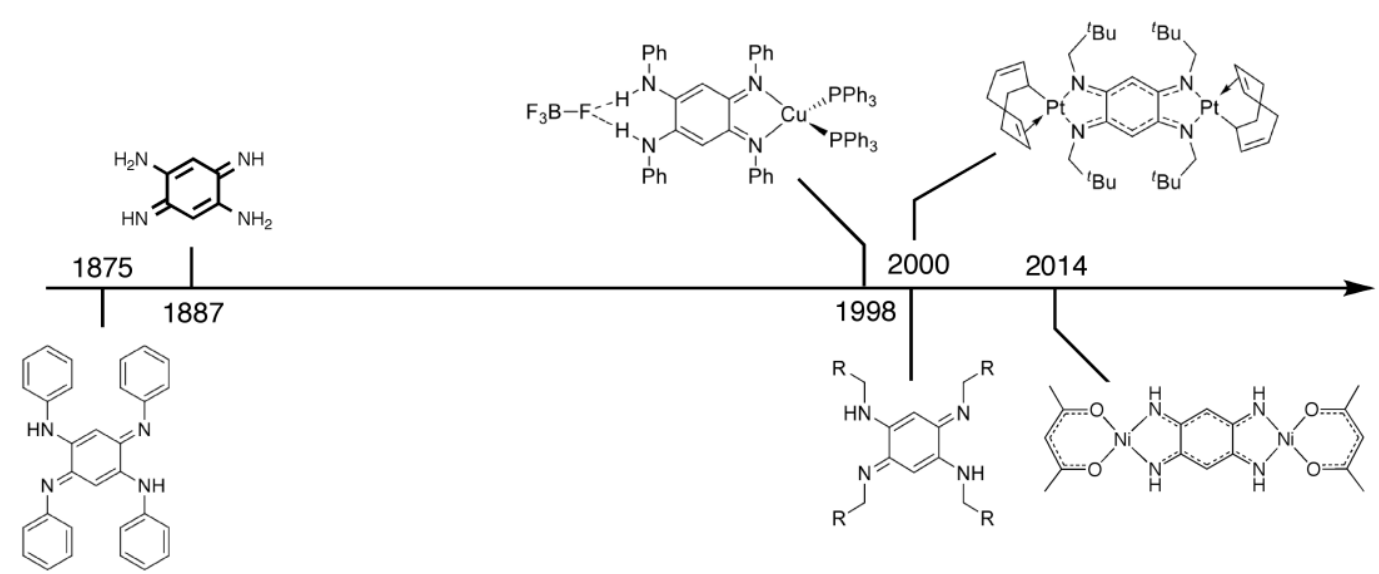

Figure 14. Timeline of BQMls synthesis and use as ligand. 
In 2014, our group reported the first direct metalation of unsubstituted DBQDI (127 years after its first report), revealing a drastic different behavior by comparison with the $N$-substituted analogues. Because of its possible isomerization process upon coordination, 2,5-diamino-1,4benzoquinonediimines (DABQDI) can be viewed as a ligand that combines the structural elements of ortho- and para-benzoquinonediimines (o-BQDI and $p-B Q D I)$ which are bidentate monotopic and monodentade ditopic ligands, respectively. These two classes of BQDI ligands have been also reviewed in order to parallel their properties to those of the complexes based on DABQDI depending on the metal center(s). For instance, the well-known non-innocent, i.e. redox active, o-BQDI ligands - which play a crucial role in the complexes depending on the degree of $\pi$-backdonation - might be used as model for understanding the properties of the mononuclear compounds based on $o$-DABQDI. Similarly, $p$-BQDI bridging ligands can be viewed as model compounds for highlighting the influence of two $6 \pi$-subunits in DABQDI ligands in the metal-metal interactions of the dinuclear complexes (i.e. two conjugated pathways for DABQDI instead of one in $p$-BQDI).

In summary, 2,5-diamino-1,4-benzoquinonediimine (DABQDI) offers important possibilities into coordination chemistry because of 1 ) the presence of $\mathrm{N}$-substituents that can be so far tuned almost at will, and 2) the easy introduction of metal centers of different nature depending on the targeted application. Reports on the use of these ligands are seldom described and mainly focused on few examples among others $12 \pi$-electrons quinones. This review report in details the synthesis and coordination chemistry of $D A B Q D I$ ligands with the hope to highlight their exceptional versatility and to stimulate researchers to extend the use of these ligands and their corresponding complexes to embrace new discoveries.

\section{AKNOWLEDGEMENTS}

This work was supported by the CNRS and the Ministère de la Recherche (Paris). The authors wish to thank all the contributions cited in this review for the development of the quinonediimine chemistry. O. S. expresses his warmest thanks to Pierre Braunstein for the five wonderful years spent working together.

\section{REFERENCES}

[1] E.R. Brown, Quinonediimines, monoimines and related compounds, in: The Quinonoid Compounds (1988), John Wiley \& Sons, Inc., 2010, pp. 1231-1292.

[2] S. Hünig, Pure Appl. Chem., 62 (1990) 395-406.

[3] J. Moussa, H. Amouri, Angew. Chem. Int. Ed., 47 (2008) 1372-1380.

[4] J. Casado, R. Ponce Ortiz, J.T. Lopez Navarrete, Chem. Soc. Rev., 41 (2012) 5672-5686.

[5] C. Asche, Mini-Rev. Med. Chem., 5 (2005) 449-467.

[6] J. López, F. de la Cruz, Y. Alcaraz, F. Delgado, M.A. Vázquez, Med. Chem. Res., 24 (2015) 3599-3620.

[7] M.D. Ward, Chem. Soc. Rev., 24 (1995) 121-134.

[8] S. Kitagawa, S. Kawata, Coord. Chem. Rev., 224 (2002) 11-34.

[9] S. Demir, I.-R. Jeon, J.R. Long, T.D. Harris, Coord. Chem. Rev., 289-290 (2015) 149-176.

[10] B. Sarkar, D. Schweinfurth, N. Deibel, F. Weisser, Coord. Chem. Rev., 293-294 (2015) 250-262.

[11] J.L. Boyer, J. Rochford, M.-K. Tsai, J.T. Muckerman, E. Fujita, Coord. Chem. Rev., 254 (2010) 309-330.

[12] V. Lyaskovskyy, B. de Bruin, ACS Catalysis, 2 (2012) 270-279. 
[13] O.R. Luca, R.H. Crabtree, Chem. Soc. Rev., 42 (2013) 1440-1459.

[14] W. Kaim, G.K. Lahiri, Angew. Chem. Int. Ed., 46 (2007) 1778-1796; and references therein.

[15] O.J.X. Morel, R.M. Christie, Chem. Rev., 111 (2011) 2537-2561.

[16] A. Meyer, K. Fischer, Environ. Sci. Europe, 27 (2015) 11.

[17] H. Berneth, Azine Dyes, in: Ullmann's Encyclopedia of Industrial Chemistry, Wiley-VCH Verlag GmbH \& Co. KGaA, 2000.

[18] R.E. Smith, S. Updated by, Azine Dyes, in: Kirk-Othmer Encyclopedia of Chemical Technology, John Wiley \& Sons, Inc., 2000.

[19] C. Seillan, H. Brisset, O. Siri, Org. Lett., 10 (2008) 4013-4016.

[20] Q. Tang, J. Liu, H.S. Chan, Q. Miao, Chem. Eur. J., 15 (2009) 3965-3969.

[21] S.K. Roy, S. Samanta, M. Sinan, P. Ghosh, S. Goswami, J. Org. Chem., 77 (2012) 1024910259.

[22] U.H.F. Bunz, J.U. Engelhart, Chem. Eur. J., 22 (2016) 4680-4689.

[23] S. Banerjee, ARKIVOC, 2016 (2016) 82-110.

[24] J. Li, S. Chen, Z. Wang, Q. Zhang, Chem. Rec., 16 (2016) 1518-1530.

[25] P.-Y. Gu, Z. Wang, Q. Zhang, J. Mater. Chem. B, 4 (2016) 7060-7074.

[26] K. Rieder, U. Hauser, H. Siegenthaler, E. Schmidt, A. Ludi, Inorg. Chem., 14 (1975) $1902-$ 1907.

[27] S. Joss, P. Bigler, A. Ludi, Inorg. Chem., 24 (1985) 3487-3488.

[28] S. Joss, H. Reust, A. Ludi, J. Am. Chem. Soc., 103 (1981) 981-982.

[29] S. Joss, H.B. Buergi, A. Ludi, Inorg. Chem., 24 (1985) 949-954.

[30] E.F.G. Herington, J. Chem. Soc., (1959) 3633.

[31] E.H. Cutín, N.E. Katz, P.A.M. Williams, P.J. Aymonino, Trans. Met. Chem., 16 (1991) 155159.

[32] Y. Wei, C. Yang, T. Ding, Tetrahedron Lett., 37 (1996) 731-734.

[33] T. Moriuchi, T. Hirao, Acc. Chem. Res., 45 (2012) 347-360.

[34] T. Moriuchi, S. Bandoh, M. Miyaishi, T. Hirao, Eur. J. Inorg. Chem., 2001 (2001) 651-657.

[35] T. Moriuchi, M. Miyaishi, T. Hirao, Angew. Chem. Int. Ed., 40 (2001) 3042-3045.

[36] L.A.P. Kane-Maguire, G.G. Wallace, Chem. Soc. Rev., 39 (2010) 2545-2576.

[37] X. Shen, T. Moriuchi, T. Hirao, Tetrahedron Lett., 45 (2004) 4733-4736.

[38] T. Moriuchi, X. Shen, T. Hirao, Tetrahedron, 62 (2006) 12237-12246.

[39] T. Hirao, S. Fukuhara, Y. Otomaru, T. Moriuchi, Synth. Met., 123 (2001) 373-376.

[40] T. Hirao, K. lida, Chem. Commun., (2001) 431-432.

[41] X. Shen, T. Moriuchi, T. Hirao, Tetrahedron Lett., 44 (2003) 7711-7714.

[42] T. Moriuchi, J. Shiori, T. Hirao, Tetrahedron Lett., 48 (2007) 5970-5972.

[43] T. Moriuchi, X. Shen, K. Saito, S. Bandoh, T. Hirao, Bull. Chem. Soc. Jpn., 76 (2003) $595-$ 599.

[44] T. Moriuchi, Y. Takagi, T. Hirao, Eur. J. Inorg. Chem., 2008 (2008) 3877-3882.

[45] A.B.P. Lever, H. Masui, R.A. Metcalfe, D.J. Stufkens, E.S. Dodsworth, P.R. Auburn, Coord. Chem. Rev., 125 (1993) 317-331.

[46] A. Mederos, S. Domínguez, R. Hernández-Molina, J.N. Sanchiz, F. Brito, Coord. Chem. Rev., 193-195 (1999) 913-939.

[47] K.P. Butin, E.K. Beloglazkina, N.V. Zyk, Russ. Chem. Rev., 74 (2005) 531.

[48] A.B.P. Lever, Coord. Chem. Rev., 254 (2010) 1397-1405.

[49] H.-L. Chan, H.-Q. Liu, B.-C. Tzeng, Y.-S. You, S.-M. Peng, M. Yang, C.-M. Che, Inorg. Chem., 41 (2002) 3161-3171.

[50] T. Bugarcic, A. Habtemariam, R.J. Deeth, F.P.A. Fabbiani, S. Parsons, P.J. Sadler, Inorg. Chem., 48 (2009) 9444-9453.

[51] S. Taheri, M. Behzad, H. Nazari, A. Khaleghian, ISRN Inorg. Chem., 2013 (2013) 6.

[52] F. Feigl, M. Fürth, Monatsh. Chem., 48 (1927) 445-450.

[53] E.I. Stiefel, J.H. Waters, E. Billig, H.B. Gray, J. Am. Chem. Soc., 87 (1965) 3016-3017.

[54] A.L. Balch, F. Röhrscheid, R.H. Holm, J. Am. Chem. Soc., 87 (1965) 2301-2302.

[55] A.L. Balch, R.H. Holm, J. Am. Chem. Soc., 88 (1966) 5201-5209.

[56] Z. Bardodej, Collect. Czech. Chem. Commun., 20 (1955) 176-179.

[57] G.S. Hall, R.H. Soderberg, Inorg. Chem., 7 (1968) 2300-2303.

[58] M.G. Miles, J.D. Wilson, Inorg. Chem., 14 (1975) 2357-2360.

[59] H.-Y. Cheng, C.-C. Lin, B.-C. Tzeng, S.-M. Peng, J. Chin. Chem. Soc., 41 (1994) 775-781.

[60] G.G. Christoph, V.L. Goedken, J. Am. Chem. Soc., 95 (1973) 3869-3875.

[61] L.F. Warren, Inorg. Chem., 16 (1977) 2814-2819.

[62] T. Ito, N. Tanaka, I. Hanazaki, S. Nagakura, Bull. Chem. Soc. Jpn., 41 (1968) 365-373. 
[63] J. Rusanova, E. Rusanov, S.I. Gorelsky, D. Christendat, R. Popescu, A.A. Farah, R. Beaulac, C. Reber, A.B.P. Lever, Inorg. Chem., 45 (2006) 6246-6262.

[64] D. Kalinina, C. Dares, H. Kaluarachchi, P.G. Potvin, A.B.P. Lever, Inorg. Chem., 47 (2008) 10110-10126.

[65] M. Kapovsky, C. Dares, E.S. Dodsworth, R.A. Begum, V. Raco, A.B.P. Lever, Inorg. Chem., 52 (2013) 169-181.

[66] H.-Y. Cheng, S.-M. Peng, Inorg. Chim. Acta, 169 (1990) 23-24.

[67] B. Milliken, L. Borer, J. Russell, M. Bilich, M.M. Olmstead, Inorg. Chim. Acta, 348 (2003) 212-216.

[68] H. Masui, A.B.P. Lever, E.S. Dodsworth, Inorg. Chem., 32 (1993) 258-267.

[69] T. Jüstel, J. Bendix, N. Metzler-Nolte, T. Weyhermüller, B. Nuber, K. Wieghardt, Inorg. Chem., 37 (1998) 35-43.

[70] S.K. Dutta, U. Beckmann, E. Bill, T. Weyhermüller, K. Wieghardt, Inorg. Chem., 39 (2000) 3355-3364.

[71] D. Herebian, K.E. Wieghardt, F. Neese, J. Am. Chem. Soc., 125 (2003) 10997-11005.

[72] E. Bill, E. Bothe, P. Chaudhuri, K. Chlopek, D. Herebian, S. Kokatam, K. Ray, T. Weyhermüller, F. Neese, K. Wieghardt, Chem. Eur. J., 11 (2005) 204-224.

[73] K. Chłopek, E. Bothe, F. Neese, T. Weyhermüller, K. Wieghardt, Inorg. Chem., 45 (2006) 6298-6307.

[74] M.M. Khusniyarov, T. Weyhermüller, E. Bill, K. Wieghardt, J. Am. Chem. Soc., 131 (2009) 1208-1221.

[75] R. Nietzki, E. Hagenbach, Chem. Ber., 20 (1887) 328-338.

[76] R. Nietzki, Chem. Ber., 20 (1887) 2114-2118.

[77] K. Ujike, S. Kudoh, M. Nakata, Chem. Phys. Lett., 409 (2005) 52-56.

[78] H. Audi, Z. Chen, A. Charaf-Eddin, A. D'Aleo, G. Canard, D. Jacquemin, O. Siri, Chem. Commun., 50 (2014) 15140-15143.

[79] R. Nietzki, Chimie des matières colorantes organiques, Hachette, 1901.

[80] C. Kimich, Chem. Ber., 8 (1875) 1026-1032.

[81] O. Fischer, E. Hepp, Chem. Ber., 21 (1888) 676-684.

[82] E.v. Bandrowski, Monatsh. Chem., 10 (1889) 123-128.

[83] A.G. Green, J. Chem. Soc., Trans., 103 (1913) 925-933.

[84] W.M. Lauer, C.J. Sunde, J. Org. Chem., 03 (1938) 261-264.

[85] C.J. Sunde, W.M. Lauer, J. Org. Chem., 17 (1952) 609-612.

[86] H.E. Cox, Analyst, 58 (1933) 738-748.

[87] H.E. Cox, Analyst, 59 (1934) 3-11.

[88] M. Altman, M.M. Rieger, J. Soc. Cosmetic Chemists, 19 (1968) 141-148.

[89] K. Ohno, H. Maruyama, T. Fujihara, A. Nagasawa, Acta Crystallogr. E, 70 (2014) о3030304 .

[90] A.J. Blake, P. Hubberstey, D.J. Quinlan, Acta Crystallogr. C, 52 (1996) 1774-1776.

[91] K. Ohno, T. Fujihara, A. Nagasawa, Acta Crystallogr. E, 70 (2014) o495-o496.

[92] O. Siri, P. Braunstein, Chem. Commun., (2000) 2223-2224.

[93] O. Siri, P. Braunstein, M.-M. Rohmer, M. Bénard, R. Welter, J. Am. Chem. Soc., 125 (2003) 13793-13803.

[94] C. Seillan, P. Braunstein, O. Siri, Eur. J. Org. Chem., 2008 (2008) 3113-3117.

[95] T. Wenderski, K.M. Light, D. Ogrin, S.G. Bott, C.J. Harlan, Tetrahedron Lett., 45 (2004) $6851-6853$.

[96] D.M. Khramov, A.J. Boydston, C.W. Bielawski, Org. Lett., 8 (2006) 1831-1834.

[97] K. Ohno, A. Nagasawa, T. Fujihara, Dalton Trans., 44 (2015) 368-376.

[98] M. Abdelhameed, A. Langlois, D. Fortin, P.-L. Karsenti, P.D. Harvey, Chem. Commun., 50 (2014) 11214-11217.

[99] H. Lei, S.M. Aly, P.-L. Karsenti, D. Fortin, P.D. Harvey, Organometallics, 36 (2017) 572 581.

[100] J. Andeme Edzang, Z. Chen, H. Audi, G. Canard, O. Siri, Org. Lett., 18 (2016) 5340-5343.

[101] K. Elbl, C. Krieger, H.A. Staab, Angew. Chem. Int. Ed., 25 (1986) 1023-1024.

[102] C.J. Adams, R.C. da Costa, R. Edge, D.H. Evans, M.F. Hood, J. Org. Chem., 75 (2010) 1168-1178.

[103] A. Peters, E. Kaifer, H.-J. Himmel, Eur. J. Org. Chem., 2008 (2008) 5907-5914.

[104] C. Kitamura, S. Tanaka, Y. Yamashita, Chem. Mater., 8 (1996) 570-578.

[105] F. Zhang, J. Bijleveld, E. Perzon, K. Tvingstedt, S. Barrau, O. Inganas, M.R. Andersson, J. Mater. Chem., 18 (2008) 5468-5474. 
[106] A.P. Zoombelt, M. Fonrodona, M.G.R. Turbiez, M.M. Wienk, R.A.J. Janssen, J. Mater. Chem., 19 (2009) 5336-5342.

[107] E. Wang, L. Hou, Z. Wang, S. Hellström, W. Mammo, F. Zhang, O. Inganäs, M.R. Andersson, Org. Lett., 12 (2010) 4470-4473.

[108] L.-P. Zhang, K.-J. Jiang, G. Li, Q.-Q. Zhang, L.-M. Yang, J. Mater. Chem. A, 2 (2014) $14852-14857$.

[109] P. Biegger, M. Schaffroth, K. Brodner, O. Tverskoy, F. Rominger, U.H.F. Bunz, Chem. Commun., 51 (2015) 14844-14847.

[110] B.D. Lindner, F. Paulus, A.L. Appleton, M. Schaffroth, J.U. Engelhart, K.M. Schelkle, O. Tverskoy, F. Rominger, M. Hamburger, U.H.F. Bunz, Journal of Materials Chemistry C, 2 (2014) 9609-9612.

[111] T.L. Tam, H. Li, F. Wei, K.J. Tan, C. Kloc, Y.M. Lam, S.G. Mhaisalkar, A.C. Grimsdale, Org. Lett., 12 (2010) 3340-3343.

[112] J. Zhang, T.C. Parker, W. Chen, L. Williams, V.N. Khrustalev, E.V. Jucov, S. Barlow, T.V. Timofeeva, S.R. Marder, J. Org. Chem., 81 (2016) 360-370.

[113] H. Rumpel, H.H. Limbach, J. Am. Chem. Soc., 111 (1989) 5429-5441.

[114] S. Dähne, D. Leupold, Angew. Chem. Int. Ed., 5 (1966) 984-993.

[115] M. Elhabiri, O. Siri, A. Sornosa-Tent, A.-M. Albrecht-Gary, P. Braunstein, Chem. Eur. J., 10 (2004) 134-141.

[116] I.-R. Jeon, J.G. Park, D.J. Xiao, T.D. Harris, J. Am. Chem. Soc., 135 (2013) 16845-16848.

[117] J.-P. Taquet, O. Siri, J.-P. Collin, A. Messaoudi, P. Braunstein, N. J. Chem., 29 (2005) 188-192.

[118] H. Masui, A.L. Freda, M.C. Zerner, A.B.P. Lever, Inorg. Chem., 39 (2000) 141-152.

[119] D. Kumbhakar, B. Sarkar, A. Das, A.K. Das, S.M. Mobin, J. Fiedler, W. Kaim, G.K. Lahiri, Dalton Trans., (2009) 9645-9652.

[120] J. Rall, A.F. Stange, K. Hübler, W. Kaim, Angew. Chem. Int. Ed., 37 (1998) 2681-2682.

[121] S. Frantz, J. Rall, I. Hartenbach, T. Schleid, S. Záliš, W. Kaim, Chem. Eur. J., 10 (2004) 149-154.

[122] P. Braunstein, A. Demessence, O. Siri, J.-P. Taquet, C. R. Chim., 7 (2004) 909-913.

[123] K. Ohno, T. Fujihara, A. Nagasawa, Polyhedron, 81 (2014) 715-722.

[124] H.-Y. Cheng, G.-H. Lee, S.-M. Peng, Inorg. Chim. Acta, 191 (1992) 25-27.

[125] S. Krupski, J.V. Dickschat, A. Hepp, T. Pape, F.E. Hahn, Organometallics, 31 (2012) 20782084.

[126] A. Peters, C. Trumm, M. Reinmuth, D. Emeljanenko, E. Kaifer, H.-J. Himmel, Eur. J. Inorg. Chem., 2009 (2009) 3791-3800.

[127] C. Trumm, O. Hübner, E. Kaifer, H.-J. Himmel, Eur. J. Inorg. Chem., 2010 (2010) 31023108.

[128] D. Emeljanenko, A. Peters, N. Wagner, J. Beck, E. Kaifer, H.-J. Himmel, Eur. J. Inorg. Chem., 2010 (2010) 1839-1846.

[129] S. Stang, A. Lebkücher, P. Walter, E. Kaifer, H.-J. Himmel, Eur. J. Inorg. Chem., 2012 (2012) 4833-4845.

[130] C. Trumm, S. Stang, B. Eberle, E. Kaifer, N. Wagner, J. Beck, T. Bredow, N. Meyerbröker, M. Zharnikov, O. Hübner, H.-J. Himmel, Eur. J. Inorg. Chem., 2012 (2012) 3156-3167.

[131] J.-P. Taquet, O. Siri, P. Braunstein, R. Welter, Inorg. Chem., 45 (2006) 4668-4676.

[132] O. Siri, J.-P. Taquet, J.-P. Collin, M.-M. Rohmer, M. Bénard, P. Braunstein, Chem. Eur. J., 11 (2005) 7247-7253.

[133] M.B. Robin, P. Day, Adv. Inorg. Chem. Radiochem., 10 (1968) 247-422.

[134] Y.-B. Huang, G.-R. Tang, G.-Y. Jin, G.-X. Jin, Organometallics, 27 (2008) 259-269.

[135] Y. Su, Y. Zhao, J. Gao, Q. Dong, B. Wu, X.-J. Yang, Inorg. Chem., 51 (2012) 5889-5896.

[136] D. Schweinfurth, M.M. Khusniyarov, D. Bubrin, S. Hohloch, C.-Y. Su, B. Sarkar, Inorg. Chem., 52 (2013) 10332-10339.

[137] N. Deibel, M.G. Sommer, S. Hohloch, J. Schwann, D. Schweinfurth, F. Ehret, B. Sarkar, Organometallics, 33 (2014) 4756-4765.

[138] J.A. DeGayner, I.-R. Jeon, T.D. Harris, Chem. Sci., 6 (2015) 6639-6648.

[139] O. Siri, P. Braunstein, J.-P. Taquet, J.-P. Collin, R. Welter, Dalton Trans., (2007) 1481 1483. 